University of South Florida

DIGITAL COMMONS

Digital Commons @ University of

@ UNIVERSITY OF SOUTH FLORIDA

South Florida

6-15-1999

\title{
West Florida Shelf Response to Upwelling Favorable Wind Forcing: Kinematics
}

\section{Zhenjiang Li}

University of South Florida

Robert H. Weisberg

University of South Florida, weisberg@marine.usf.edu

Follow this and additional works at: https://digitalcommons.usf.edu/msc_facpub

Part of the Marine Biology Commons

\section{Scholar Commons Citation}

$\mathrm{Li}$, Zhenjiang and Weisberg, Robert H., "West Florida Shelf Response to Upwelling Favorable Wind Forcing: Kinematics" (1999). Marine Science Faculty Publications. 122.

https://digitalcommons.usf.edu/msc_facpub/122

This Article is brought to you for free and open access by the College of Marine Science at Digital Commons @ University of South Florida. It has been accepted for inclusion in Marine Science Faculty Publications by an authorized administrator of Digital Commons @ University of South Florida. For more information, please contact digitalcommons@usf.edu. 


\title{
West Florida shelf response to upwelling favorable wind forcing: Kinematics
}

\author{
Zhenjiang $\mathrm{Li}$ and Robert $\mathrm{H}$. Weisberg \\ Department of Marine Science, University of South Florida, St. Petersburg
}

\begin{abstract}
The barotropic responses of the west Florida continental shelf to idealized upwelling favorable alongshore and offshore wind stresses are studied using the threedimensional, time-dependent, primitive equation Princeton Ocean Model (POM). When forced with uniform winds, the shelf circulation evolves quickly to a quasi steady state. A southeastward alongshore wind lowers sea level along the coast and drives a southeastward coastal jet with a relatively weak northwestward return flow farther offshore. A southwestward offshore wind lowers sea level along the west Florida coast and raises sea level along the Panhandle coast. Two independent circulation gyres are set up in association with these regionally different sea level distributions: an anticyclonic gyre off the west Florida coast consisting of a southeastward coastal jet and a broad return flow over the middle shelf and a cyclonic gyre off the Panhandle coast consisting of a strong northwestward coastal jet and an adjacent narrow southeastward undercurrent. These gyres are separated by the Big Bend region. In both cases (alongshore and offshore wind forcing) the circulations are fully three-dimensional, with opposing surface and bottom boundary layer flows accounting for the across-shelf transports. The shapes of the coastline and the isobaths are important determinants of the shelf-wide responses. Several locally maximum upwelling regions are identified for geometrical reasons. These include the Panhandle coast south of Apalachicola Bay, the west Florida coast south of Tampa Bay, along the Florida Keys, and at the shelf break where topographic Rossby waves are evident.
\end{abstract}

\section{Introduction}

The west Florida continental shelf (WFS) is among the broadest continental shelves in North America. Located at the eastern edge of the Gulf of Mexico, it is bounded by coastline in the north and east, and it is partially blocked by the Florida Keys in the south (Figure 1). With the $100 \mathrm{~m}$ isobath being positioned some $80 \mathrm{~km}, 200 \mathrm{~km}$, and $250 \mathrm{~km}$ offshore in its northern, central, and southern regions, respectively, the WFS has fairly broad middle and inner-shelf regimes that are distinguishable from the outer shelf (shelf break) regime. The WFS is also fully three dimensional since the relative coastline and isobath geometries result in regions of either convergent or divergent isobaths, notably along the Panhandle coast in the north, the Big Bend in the northeast, and the west Florida coast in the east.

Observations [e.g., Niiler, 1976; Koblinsky and Niiler, 1980; Mitchum and Sturges, 1982; Cragg et al., 1983; Marmorino, 1983; Mitchum and Clarke, 1986b; Weisberg et al., 1996a, b] show that the WFS circulation and sea level variations are highly correlated with wind stress. The circulation also varies over a wide range of space scales and timescales, forced by baroclinic effects originating either with the Loop Current at the shelf break [e.g., Paluszkiewicz et al., 1983] or with a combination of seasonally varying coastal and surface buoyancy fluxes. Adding the effects of nonlinear, turbulent interactions that may occur between the various scales of motion, the shelf-wide responses to external forcing are intrinsically complex.

Copyright 1999 by the American Geophysical Union.

Paper number 1999JC900073.

0148-0227/99/1999JC900073\$09.00
Parallel efforts at in situ and numerical model experimentations are presently in place on the WFS for improved understanding of environmental issues. Because of the factors noted above, we adopted a stepwise approach to model experimentation, utilizing the primitive equation Princeton Ocean Model (POM) described by Blumberg and Mellor [1987] and adding levels of complexity in a systematic way to facilitate model interpretations relative to observations. A first set of model experiments consists of initial value problems in which a constant density shelf, initially at rest, is acted upon by spatially uniform, time-independent, upwelling favorable winds directed either alongshore or offshore relative to the west Florida coast. While the model is fully nonlinear, to the extent that the linear terms control the dynamics, the shelf response to uniform winds from any coordinate direction may be thought of in terms of the responses to these two coordinate directions. The purpose of this paper therefore is to provide a relatively simple framework within which the shelf-wide responses to synoptic scale wind forcing may be interpreted independently of other causative factors.

Section 2 describes the model and its formulation relative to previous numerical model applications on the WFS. Sections 3 and 4 develop the kinematics of the circulation responses in the alongshore and offshore wind-forced experiments, respectively. The coastal jet and sea level responses of the inner shelf, defined as the region of interacting surface and bottom Ekman layers [e.g., Mitchum and Clarke, 1986a; Lentz, 1995], are particularly evident. The spin-up, occurring primarily over a pendulum day, follows a classical Ekman-geostrophic route in which the across-shelf divergence in the surface wind-driven transport causes a sea level slope and an associated alongshore 

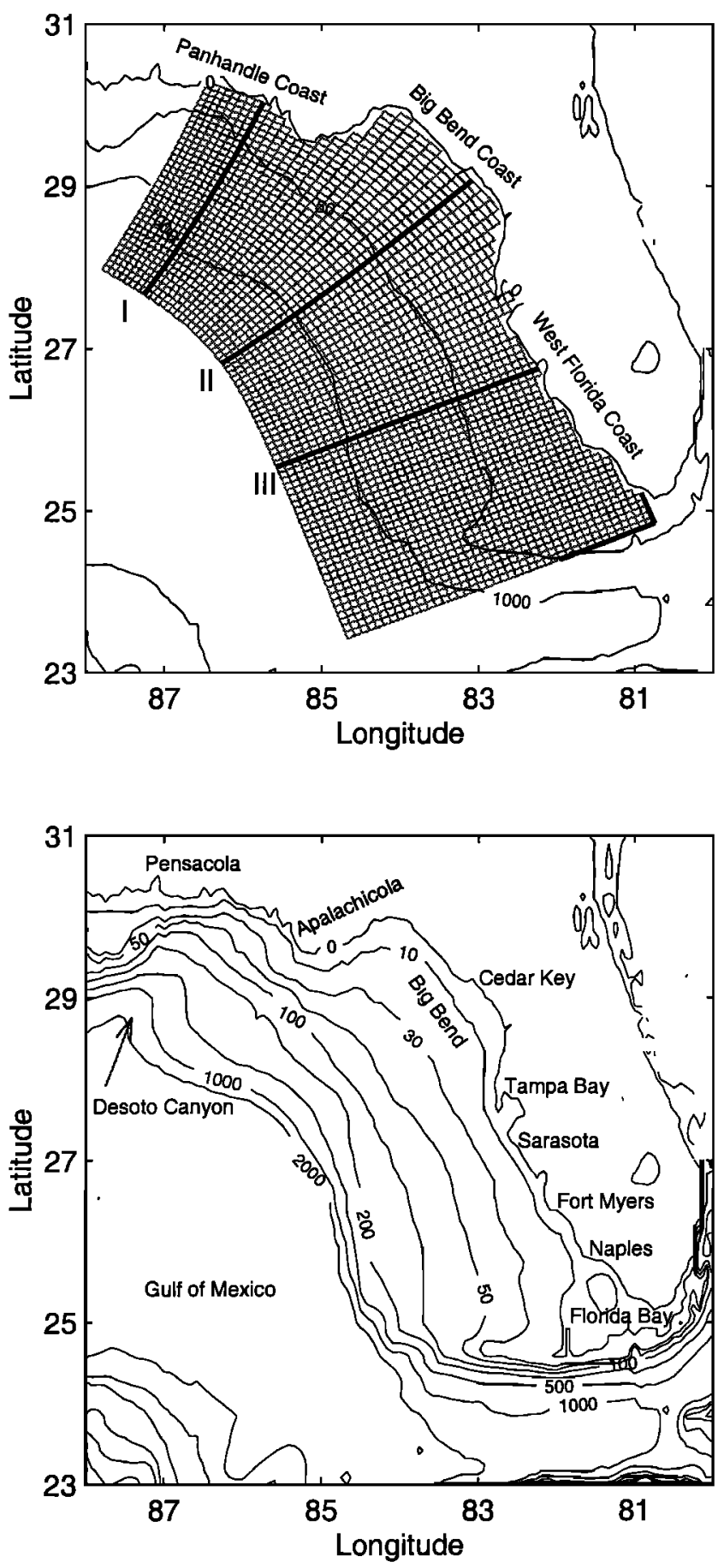

Figure 1. West Florida (bottom) continental shelf bathymetry and (top) model domain with an average grid size of about $9 \mathrm{~km}$. Bold lines denote cross sections for later analysis. From north to south these are labeled sections I, II, and III. The remaining bold line in the south denotes partial closure of the southern boundary by the Florida Keys.

jet that, in turn, effects the bottom Ekman layer transport necessary to complete the across-shelf transport circuit. The across-shelf scale of the response is therefore a frictional scale set by the turbulence. Additional three-dimensional effects, including countercurrents at midshelf, then evolve on longer timescales by virtue of the WFS geometry. Section 5 describes the sensitivity of the results to the model turbulence parame- terization and wind stress magnitude. Section 6 then offers a summary and discussion. Dynamical analyses that quantify the spatially varying momentum balances are developed separately by $\mathrm{Z}$. $\mathrm{Li}$ and $\mathrm{R}$. H. Weisberg (West Florida continental shelf response to upwelling favorable wind forcing: Dynamics, submitted to Journal of Geophysical Research, 1999). Here we exploit just the three-dimensional aspects of the flow fields.

\section{Model Development}

\subsection{Previous Numerical Models of the West Florida Shelf}

Relative to the many applications of numerical circulation models on continental shelves, those specific to the WFS are limited, this despite the fact that the Gulf of Mexico Loop Current is extensively studied [e.g., Blumberg and Mellor, 1985; Oey, 1995]. Marmorino [1982] used a linear, two-dimensional, steady state model with realistic coastline and bathymetry to examine the barotropic sea level response of the shelf to constant, uniform wind forcing from different coordinate directions. The model gave realistic sea surface slopes, trapped to the coast with an e-folding scale consistent with the arrested topographic wave scales of Csanady (1978) and Winant [1979]. Hsueh et al. [1982] added time dependence to a linear, twodimensional model to study the barotropic sea level and circulation responses of the WFS to constant, uniform wind forcing directed either alongshore or offshore but with simplified geometry. Idealized time-dependent forcing typical of a wintertime cold front was also analyzed. This model produced sea level fluctuations at the coast in reasonable agreement with observations, and it generated topographic Rossby waves at the shelf break. The offshore scale of the sea level fluctuations was much smaller than a barotropic Rossby radius of deformation and similar to that found by Marmorino [1982]. As vertically integrated models, neither of these was able to explore the kinematics of the circulation, its vertical structures leading to cross-isobath transports, or the dynamics involved. Cooper [1987] employed a linear baroclinic model using a Galerkin scheme in the vertical but with coarse resolution and unrealistic geometry. Several experiments were performed, including responses to idealized seasonal forcing. Although direct comparisons with observations were minimal, the differences between the near-surface and near-bottom flows suggested that three dimensionality is important to describe the redistribution of mass that occurs as the shelf adjusts to changes in wind forcing.

\subsection{Princeton Ocean Model Application}

Building upon the work of Marmorino [1982], Hsueh et al. [1982], and Cooper [1987], we sought increased horizontal resolution to realistically represent the coastline and bathymetry and improved vertical flow field structure to resolve the mechanisms of mass adjustment. Thus we set out to perform similar constant, spatially uniform wind-forced experiments, but with a fully three-dimensional, time-dependent, primitive equation model that could be further modified to include more complicated forcing functions and baroclinicity. The Princeton Ocean Model (POM) described by Blumberg and Mellor [1987] was selected for this purpose. The model has several important features. First, it has an embedded turbulence closure submodel [Mellor and Yamada, 1974, 1982; Galperin et al., 1988] for parameterizing the vertical turbulent eddy coefficients. Second, it employs a sigma coordinate in the vertical, which, with the turbulence closure submodel, is well suited to study the 
nonlinear dynamics over a shallow, gently sloping continental shelf. Finally, orthogonal curvilinear coordinates in the horizontal are convenient since the isobaths generally tend to run parallel to the coastline over much of the WFS. There are numerous successful applications of the POM to estuarine and continental shelf circulation studies, such as the works of Blumberg and Mellor (1985), Ezer and Mellor [1994], Miller and Lee [1995a, b], and Allen et al. [1995].

The POM equations governing the conservation of mass and momentum under a hydrostatic approximation, using orthogonal curvilinear coordinates $(\xi, s)$ horizontally and a sigma coordinate $(\sigma)$ vertically, are provided below. Equations for potential temperature and salinity conservation are omitted because they are not active in this barotropic study. Table 1 defines the various symbols, and the turbulence closure submodel is discussed in the appendix.

$$
\begin{aligned}
& h_{1} h_{2} \frac{\partial \eta}{\partial t}+\frac{\partial}{\partial \xi}\left(h_{2} u D\right)+\frac{\partial}{\partial \varsigma}\left(h_{1} v D\right)+h_{1} h_{2} \frac{\partial \omega}{\partial \sigma}=0 \\
& \frac{\partial\left(h_{1} h_{2} u D\right)}{\partial t}+\frac{\partial}{\partial \xi}\left(h_{2} u^{2} D\right)+\frac{\partial}{\partial \varsigma}\left(h_{1} u v D\right)+h_{1} h_{2} \frac{\partial(\omega u)}{\partial \sigma} \\
& +D v\left(-v \frac{\partial h_{2}}{\partial \xi}+u \frac{\partial h_{1}}{\partial \varsigma}-h_{1} h_{2} f\right) \\
& =-g h_{2} D \frac{\partial \eta}{\partial \xi}-\frac{g h_{2} D^{2}}{\rho_{0}} \int_{\sigma}^{0}\left(\frac{\partial \rho}{\partial \xi}-\frac{\sigma}{D} \frac{\partial D}{\partial \xi} \frac{\partial \rho}{\partial \sigma}\right) d \sigma \\
& -D \frac{h_{2}}{\rho_{0}} \frac{\partial P_{a}}{\partial \xi}+\frac{\partial}{\partial \xi}\left(2 A_{m} \frac{h_{2}}{h_{1}} D \frac{\partial u}{\partial \xi}\right)+\frac{\partial}{\partial \zeta}\left(A_{m} \frac{h_{1}}{h_{2}} D \frac{\partial u}{\partial \varsigma}\right) \\
& +\frac{\partial}{\partial \varsigma}\left(A_{m} D \frac{\partial v}{\partial \xi}\right)+\frac{h_{1} h_{2}}{D} \frac{\partial}{\partial \sigma}\left(K_{m} \frac{\partial u}{\partial \sigma}\right) \\
& \frac{\partial\left(h_{1} h_{2} v D\right)}{\partial t}+\frac{\partial}{\partial \xi}\left(h_{2} u v D\right)+\frac{\partial}{\partial \varsigma}\left(h_{1} v^{2} D\right)+h_{1} h_{2} \frac{\partial(\omega v)}{\partial \sigma} \\
& +D u\left(-u \frac{\partial h_{1}}{\partial \varsigma}+v \frac{\partial h_{2}}{\partial \xi}+h_{1} h_{2} f\right) \\
& =-g h_{1} D \frac{\partial \eta}{\partial \varsigma}-\frac{g h_{1} D^{2}}{\rho_{0}} \int_{\sigma}^{0}\left(\frac{\partial \rho}{\partial \varsigma}-\frac{\sigma}{D} \frac{\partial D}{\partial \varsigma} \frac{\partial \rho}{\partial \sigma}\right) d \sigma \\
& -D \frac{h_{1}}{\rho_{0}} \frac{\partial P_{a}}{\partial \varsigma}+\frac{\partial}{\partial \varsigma}\left(2 A_{m} \frac{h_{1}}{h_{2}} D \frac{\partial v}{\partial \varsigma}\right)+\frac{\partial}{\partial \xi}\left(A_{m} \frac{h_{2}}{h_{1}} D \frac{\partial v}{\partial \xi}\right) \\
& +\frac{\partial}{\partial \xi}\left(A_{m} D \frac{\partial u}{\partial \varsigma}\right)+\frac{h_{1} h_{2}}{D} \frac{\partial}{\partial \sigma}\left(K_{m} \frac{\partial v}{\partial \sigma}\right)
\end{aligned}
$$

The boundary conditions at the surface and bottom are

$$
\begin{gathered}
\omega(0)=0 \\
\omega(-1)=0 \\
\frac{K_{m}}{D}\left(\frac{\partial u(0)}{\partial \sigma}\right)=\frac{\tau_{\xi}}{\rho_{0}} \\
\frac{K_{m}}{D}\left(\frac{\partial u(-1)}{\partial \sigma}\right)=C_{b}\left(u_{b}^{2}+v_{b}^{2}\right)^{1 / 2} u_{b} \\
\frac{K_{m}}{D}\left(\frac{\partial v(0)}{\partial \sigma}\right)=\frac{\tau_{\xi}}{\rho_{0}}
\end{gathered}
$$

Table 1. Summary of the Symbols Used in the Model Equations and Boundary Conditions

$$
\begin{aligned}
& \text { Symbol Description } \\
& \begin{array}{ll}
t & \text { time } \\
\xi, s & \text { horizontal orthogonal curvilinear coordinates, directing }
\end{array} \\
& \text { southeastward and onshore, respectively } \\
& h_{1}, h_{2} \quad \text { transformation metric coefficients of the horizontal } \\
& \text { coordinates from the regular Cartesian system }(x, y) \\
& \text { to the orthogonal curvilinear system }(\xi, s) \\
& H_{0} \quad \text { average water depth relative to the geoid } \\
& \eta \quad \text { free surface elevation } \\
& \sigma \quad \text { sigma coordinate, defined as } \sigma=(z-\eta) /\left(H_{0}+\eta\right) ; z \\
& \text { is the original Cartesian vertical coordinate, } \sigma=0 \\
& \text { denotes the free surface, and } \sigma=-1 \text { denotes the } \\
& \text { bottom } \\
& \omega=w-\frac{1}{h_{1} h_{2}}\left[h_{2} u\left(\sigma \frac{\partial D}{\partial \xi}+\frac{\partial \eta}{\partial \xi}\right)\right. \\
& \left.+h_{1} v\left(\sigma \frac{\partial D}{\partial \varsigma}+\frac{\partial \eta}{\partial \varsigma}\right)\right]-\left(\sigma \frac{\partial D}{\partial t}+\frac{\partial \eta}{\partial t}\right)
\end{aligned}
$$

$D \quad$ instantaneous water depth, $D=H_{0}+\eta$

$f \quad$ Coriolis parameter, $f=2 \Omega \sin \varphi$, where $\Omega=7.27 \times$

$10^{-5} \mathrm{~s}^{-1}$ and $\varphi$ is the latitude

$g \quad$ acceleration of gravity $\left(9.8 \mathrm{~m} \mathrm{~s}^{-2}\right)$

$P_{a} \quad$ atmospheric pressure at sea surface, constant

$\rho_{0}(=\rho) \quad$ mean density, set to $1.023 \times 10^{3} \mathrm{~kg} \mathrm{~m}^{-3}$;

$K_{m} \quad$ vertical eddy coefficient for vertical turbulent momentum mixing

$A_{m} \quad$ horizontal eddy coefficient calculated from the Smagorinsky formulation:

$$
A_{m}=\sqrt{C h_{1} h_{2}\left[\left(\frac{\partial u}{\partial \xi}\right)^{2}+\frac{1}{2}\left(\frac{\partial v}{\partial \xi}+\frac{\partial u}{\partial \varsigma}\right)^{2}+\left(\frac{\partial v}{\partial \varsigma}\right)^{2}\right]}
$$

where $C=0.1$

$\tau_{\xi}, \tau_{\mathrm{s}} \quad$ surface wind stress components in $(\xi, \varsigma)$ directions, respectively

$C_{b} \quad$ bottom drag coefficient, $C_{b}=\operatorname{MAX}\left\{k^{2}\left[\ln \left(1+\sigma_{n b}\right)\right.\right.$ $\left.\left.\left.H_{0} / z_{0}\right)\right]^{-2}, 2.5 \times 10^{-3}\right\} ; \kappa=0.4$ is the von Karman constant, $\sigma_{n b}$ is the $\sigma$ position of the grid point next to the bottom, and $z_{0}(=0.01 \mathrm{~m})$ is the bottom roughness constant;

$u_{b}, v_{b} \quad$ bottom velocity components evaluated at the grid next to the bottom

$$
\frac{K_{m}}{D}\left(\frac{\partial v(-1)}{\partial \sigma}\right)=C_{b}\left(u_{b}^{2}+v_{b}^{2}\right)^{1 / 2} v_{b}
$$

At the coastal boundaries the velocity components are zero owing to the no-slip and normal flow conditions. At the open boundaries the Orlanski [1976] radiation condition is adopted for all of the dynamical variables, where the radiation speed is calculated from the corresponding interior field. This treatment of the open boundaries is sufficient to maintain mass conservation over the model domain. We note that experiments performed with zero sea surface elevation along the western open boundary essentially gave the same results. However, for subsequent baroclinic calculations [ $\mathrm{Li}, 1998]$ this clamped boundary condition, with or without additional damping terms [e.g., Blumberg and Kantha, 1985], gave undesirable internal gravity wave reflections.

The model domain (Figure 1) extends about $750 \mathrm{~km}$ alongshore from the Florida Panhandle to the Florida Keys and about $450 \mathrm{~km}$ offshore from the west Florida coast. It covers 
Table 2. Spacing of the Sigma Levels

\begin{tabular}{rc}
\hline Level & $\sigma$ Spacing \\
\hline 1 & 0.000 \\
2 & 0.014 \\
3 & -0.028 \\
4 & -0.056 \\
5 & -0.111 \\
6 & -0.222 \\
7 & -0.333 \\
8 & -0.444 \\
9 & -0.556 \\
10 & -0.667 \\
11 & -0.778 \\
12 & -0.889 \\
13 & -0.944 \\
14 & -0.972 \\
15 & -0.986 \\
16 & -1.000 \\
\hline
\end{tabular}

the entire WFS, and it extends sufficiently westward into the Gulf of Mexico so that the region of the shelf break is resolved. Realistic shelf topography (obtained from the Data Support Section of the Computing Division of the National Center for Atmospheric Research) is used, with $1500 \mathrm{~m}$ being the maximum depth beyond the shelf break and $5 \mathrm{~m}$ being the minimum depth at the coastline. The horizontal computational grid size ranges from 6.5 to $15 \mathrm{~km}$, with an average of $9 \mathrm{~km}$, - providing higher resolution than in previous WFS model studies. The vertical resolution includes 16 levels that are distributed logarithmically about the middle (Table 2) to achieve finer resolution of the surface and bottom boundary layers relative to the interior flow.

The POM employs a staggered (Arakawa C) grid for horizontal spatial differencing. For time differencing the horizontal terms are treated by an explicit leapfrog scheme, whereas the vertical terms are treated implicitly. This eliminates an additional time constraint for the vertical coordinate and allows for a finer vertical resolution in the surface and bottom boundary layers. The model is also split into external and internal modes with different time steps ( $15 \mathrm{~s}$ for the external mode and $600 \mathrm{~s}$ for the internal mode), improving the efficiency with which the model is run.

\section{Southeastward Alongshore Wind Experiment}

An initial value problem is performed from a state of rest by applying a spatially uniform, time-independent wind stress of magnitude 1 dyn $\mathrm{cm}^{-2}$ oriented $150^{\circ}$ relative to true north.

\subsection{Spin-Up and Sea Surface Elevation}

The spin-up phase proceeds rapidly over the course of a pendulum day, after which the model slowly approaches a quasi steady state. Figure 2 shows the horizontal velocity component time series and their corresponding kinetic energies near the surface and bottom at a site central to the model domain $\left(28^{\circ} \mathrm{N}, 84^{\circ} \mathrm{W}\right)$. The near-surface flow is more energetic than the near-bottom flow, as expected. The initial response, consisting of an accelerating coastal jet with an offshore directed component at the surface, followed by an onshore flow component at depth, is consistent with the classical Ekmangeostrophic spin-up problem. Once the near steady state pattern is achieved (Figure 4), the near-surface flow vector at this location is oriented $\sim 45^{\circ}$ to the right of the wind stress. The time delay for the near-bottom flow to develop relative to the near-surface flow is the setup time for the surface slope since a surface slope is necessary to drive an interior geostrophic flow before a bottom Ekman layer can form in response. The end result is a left-hand turning in the bottom Ekman layer relative to the interior flow (Figure 4).

The overall response patterns also evolve rapidly to their quasi steady states, as shown for sea level and vertically averaged currents in Figure 3. The overall patterns are essentially established within 1 day, after which only the details vary, not the large scale features; that is, the day 8 patterns look very much like those on day 1 . Observations [e.g., Marmorino, 1982; Cragg et al., 1983] of coastal sea level being directly wind forced at synoptic weather timescales and lagging the wind by less than a pendulum day support this rapid spin-up finding. Because the spin-up time is less than the timescale (roughly 2-14 days) of the synoptic weather, these initial value problem results may be viewed as representative of the WFS response to the trailing edge of a typical frontal system.

The divergence of the offshore-directed Ekman transport for this southeastward alongshore wind stress experiment results in upwelling and a set down of sea level at the coast. The sea surface topography (Figure 3) shows that the offshore extent of the response is primarily contained within the 50-100 $\mathrm{m}$ isobaths, similar to that found by Marmorino [1982] and Hsueh et al. [1982]. The offshore scale is widest in the Big Bend, where the bottom slope is smallest, and narrowest in the Panhandle, where the bottom slope is largest. Thus the surface topography isolines do not exactly parallel the isobaths, leading to different regional response behaviors, to be discussed later. With the sea surface tilting down toward the coast, the coastal elevation change is dependent upon the shape of the coastline [Cragg et al., 1983]. Within the Big Bend region, where the distance between the sea surface topography nodal line and the shoreline is largest, the set down is also the largest: $33 \mathrm{~cm}$ in this case. Owing to the partial closure of the southern bound-
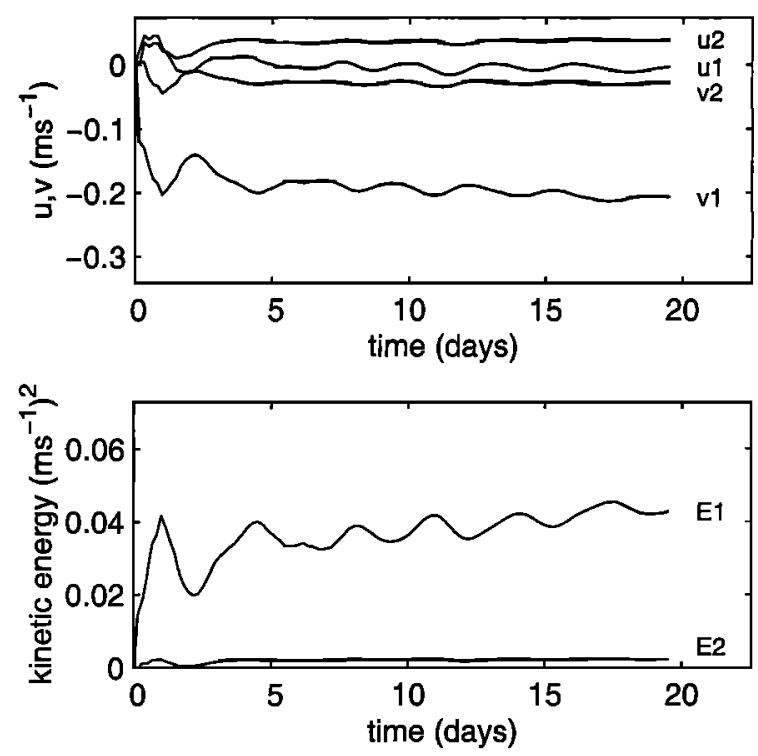

Figure 2. Kinetic energy and velocity component time series near the surface (1) and bottom (2) at $28^{\circ} \mathrm{N}, 84^{\circ} \mathrm{W}(1.31$ and $45.7 \mathrm{~m}$, respectively, at $47 \mathrm{~m}$ total depth) from the alongshore wind experiment (where 1 and 2 refer to the subscripts of the labels). 


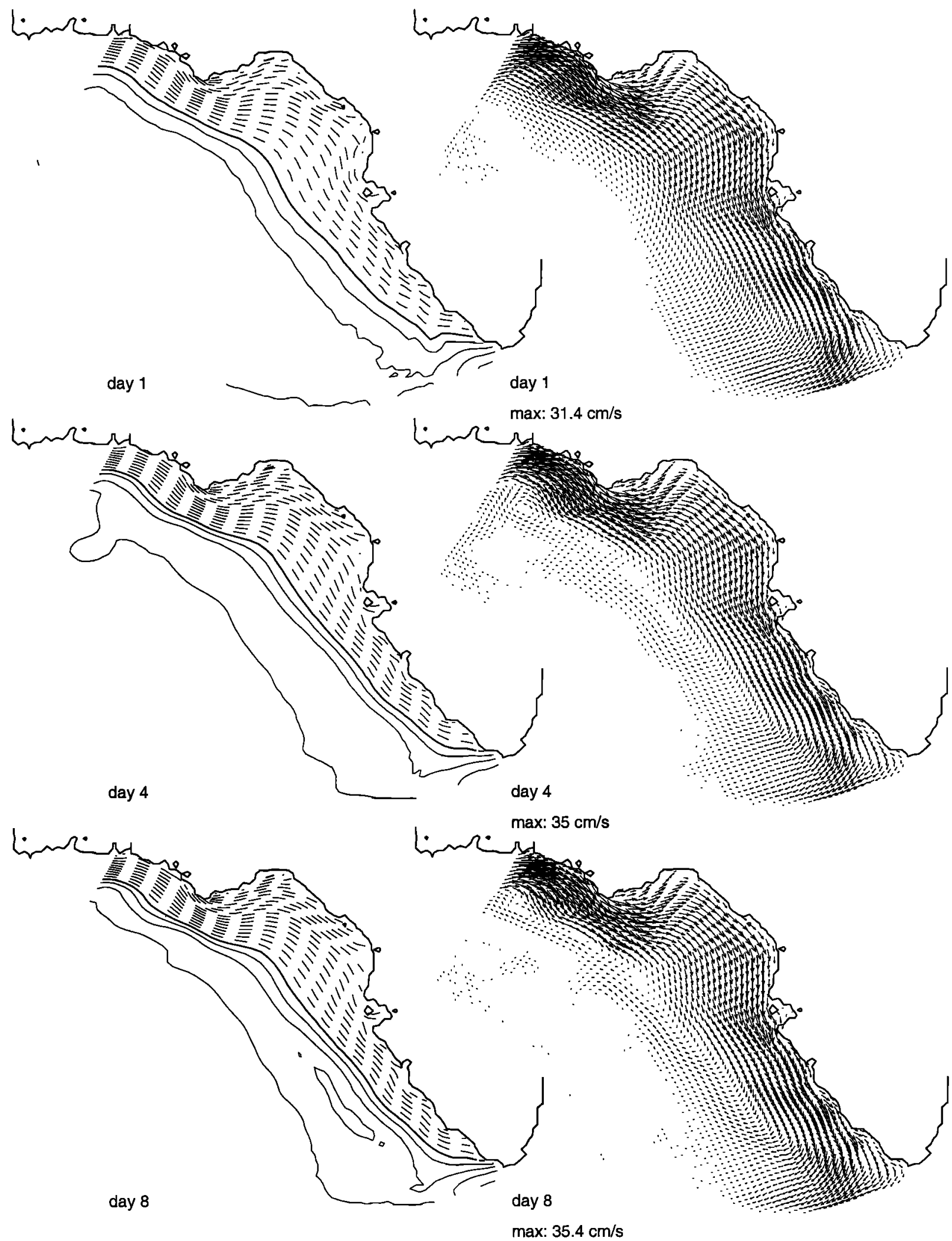

Figure 3. Sea surface elevation and depth-averaged velocity at days 1 , 4, and 8 from the alongshore wind experiment. For elevation, thick lines denote the zero contour, dashed lines are negative contours, and the contour interval is $0.01 \mathrm{~m}$. 




(a) depth-averaged (day 12). $\max : 36.2 \mathrm{~cm} / \mathrm{s}$

(b) subsurface (level 2, day 12). max: $50.7 \mathrm{~cm} / \mathrm{s}$

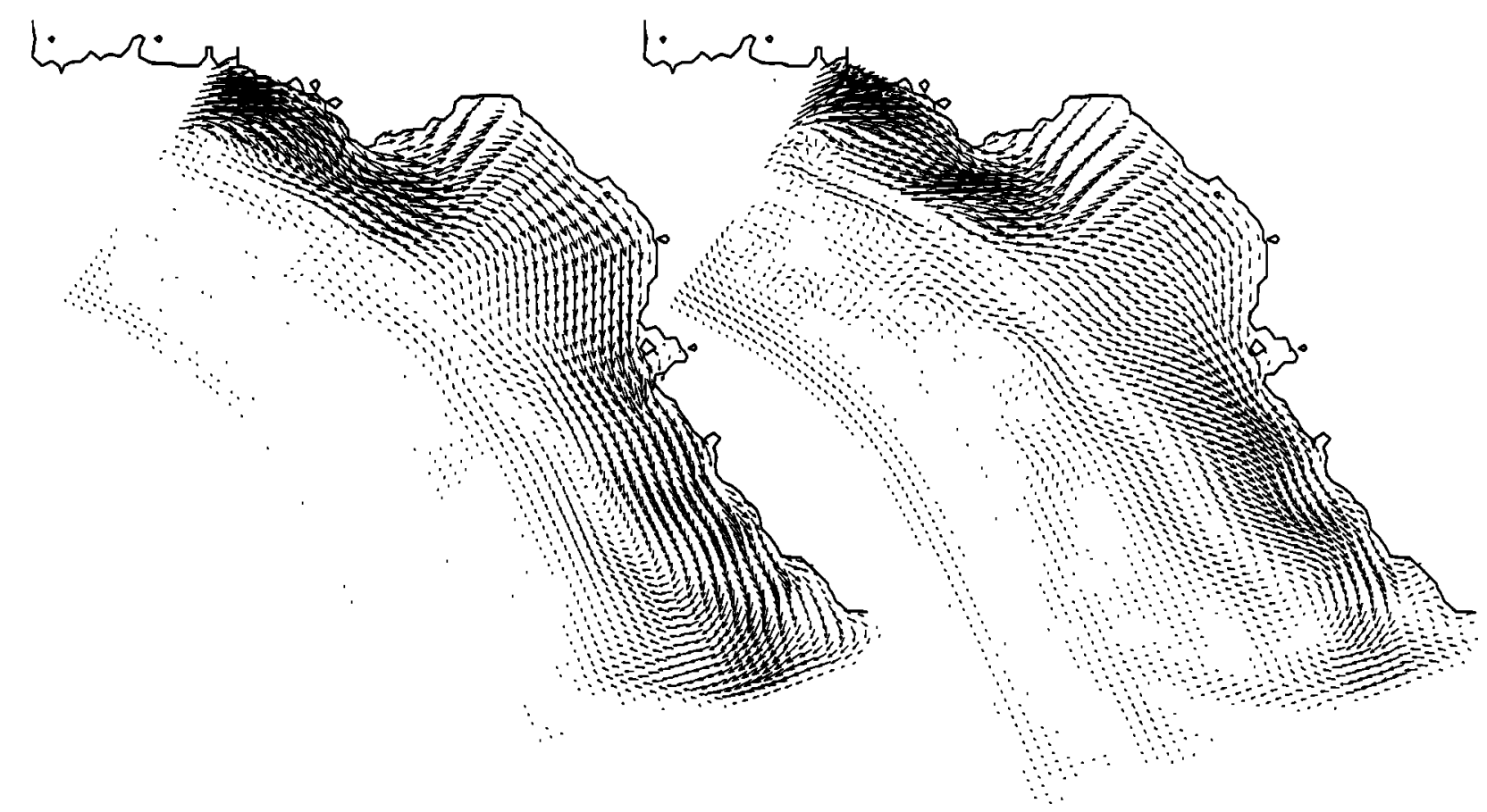

(c) middle (level 8 , day 12). max: $38.3 \mathrm{~cm} / \mathrm{s}$

(d) near-bottom (level 15, day 12). $\max : 13.4 \mathrm{~cm} / \mathrm{s}$

Figure 4. Horizontal velocity vector fields at day 12 for the alongshore wind experiment: (a) depth-averaged, (b) near-surface (sigma level 2), (c) middepth (sigma level 8), and (d) near-bottom (sigma level 15).

ary by the Florida Keys, water piles up there, in contrast to other locations along the coast. This piling up of water drives an offshore-directed flow along the southern boundary, which turns anticyclonically to feed a return flow farther offshore. The timescale to set up this return flow, which includes a subtle reversal of the across-shelf pressure gradient over the outer portion of the shelf, is longer than a pendulum day, as seen in
Figures 3 and 7. Thus the inner-shelf region sets up first, followed by the return flow farther offshore due to the geometrical effects of the coastline variations and the partial closure by the Florida Keys.

A difference exists between the process of spin-up described above with that described by other authors for a west coast ocean in response to upwelling favorable alongshore wind 
stress [e.g., Suginohara, 1982; Philander and Yoon, 1982; Blumberg and Mellor, 1987]. In all cases a downwind jet develops within the coastal region as the result of direct wind forcing and the geostrophic response to the ensuing pressure field. However, if the depth at the coast is large or baroclinicity effectively decouples the flow field from the frictional effects of the bottom, then the offshore response scale is the Rossby radius of deformation and the adjustment time is the time for coastal Kelvin or shelf waves to transit the wind-forced region. In our case the response scales and adjustment time are modified by an active bottom Ekman layer by virtue of a gradual depth variation. Mitchum and Clarke [1986a] provide an analytical basis for such frictional, inner-shelf effects, and such behavior is evident in the work of Lentz [1995] and in the two-dimensional POM experiments of Allen et al. [1995].

\subsection{Flow Field on Sigma Surfaces}

Important three-dimensional features arise on the WFS because of its unique geometry, which includes partial blocking in the south by the Florida Keys and the coastline changes within the Big Bend. These are seen in the Figure 4 horizontal velocity field maps sampled on day 12 for different sigma levels, including the depth average (Figure 4a), the near-surface level 2 (Figure $4 b$ ), the middle level 8 (Figure $4 \mathrm{c}$ ), and the nearbottom level 15 (Figure 4d). With the exception of the return flow farther offshore, the midshelf and inner-shelf features for these day 12 patterns are nearly equivalent to the patterns at any time after day 1 , because of the rapid spin-up previously shown. The midlevel and depth-averaged flow fields are similar, and they show the general nature of the flow field. An alongshore jet exists, consistent with the sea surface deformation, and it varies alongshore with the coastline and bathymetry. The coastal jet is strong and narrow on the Panhandle shelf because of tightly packed isobaths, relatively weak and broad in the Big Bend because of more widely spaced isobaths, and strong again south of Tampa Bay, and beyond Naples it begins to form a return flow because of partial blocking by the Florida Keys. This return flow originates ageostrophically in the southeast corner (it flows uphill) and then turns toward the northwest as a geostrophic flow, consistent with the surface topography. Thus a northwest oriented U-shaped pattern occurs, connecting the strong southeastward coastal jet with the relatively weak northwestward return flow.

Unlike the depth-averaged and the midlevel flow fields, the surface flow consists of both pressure field and Ekman layer related parts. The surface currents are thus discussed with respect to two regions. The first is the area with large sea surface deformation and hence the superposition of Ekman and geostrophic flows, generally shoreward of the $50 \mathrm{~m}$ isobath. The second is the area without large surface deformation and hence just containing Ekman flows. Within the coastal jet region the surface flows show a small turning to the right relative to the middepth flows, with the Ekman part adding to the geostrophic part. Over a broad expanse of the southern portion of the model domain, roughly seaward of the $50 \mathrm{~m}$ isobath, a classical Ekman flow develops directed $45^{\circ}$ to the right of the wind stress. There the northwestward return flow occurs as an undercurrent beneath the surface boundary layer. Over the northern half of the model domain, where the isobath slopes are larger and deeper water is located closer to the coast, the surface flow is directed normal (as opposed to $45^{\circ}$ ) to the wind stress. This is a consequence of sigma coordinate

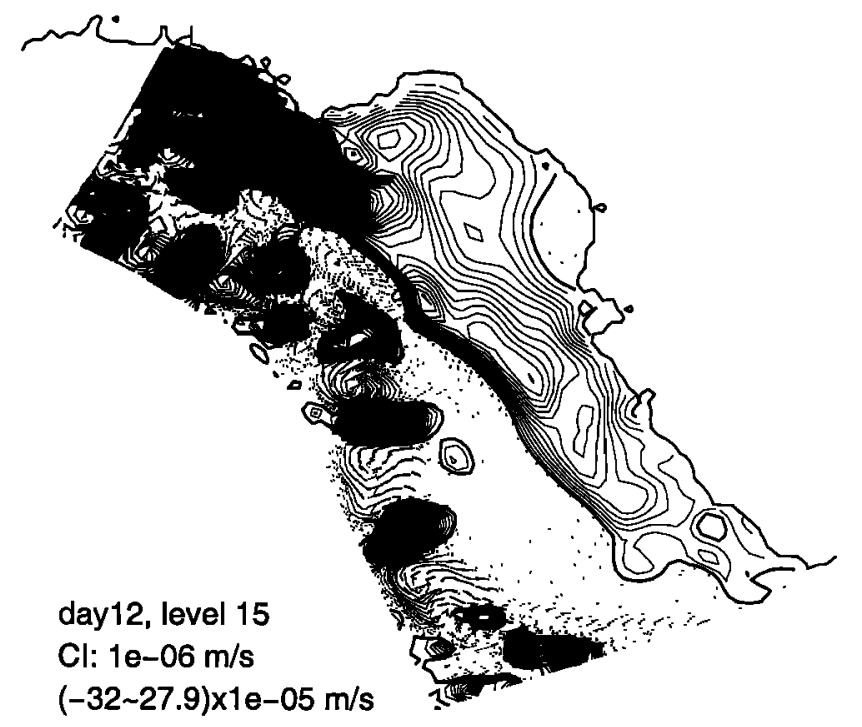

Figure 5. Vertical velocity component field at day 12 for the alongshore wind experiment, sampled near the bottom (at sigma level 15) and transformed to the $z$ coordinate of a standard rectilinear $x, y, z$ system. Solid lines denote upwelling, dotted lines denote downwelling, and the contour interval is $10^{-6} \mathrm{~m} \mathrm{~s}^{-1}$.

system stretching with depth, which renders the Ekman layer within the first two sigma levels in this region.

In the same way that the near-surface flow field shows the effects of the surface Ekman layer, the near-bottom flow field is modified by the bottom Ekman layer. Relative to the middepth currents, the bottom Ekman layer causes a left-hand turning in the near-bottom currents. This has important ramifications. In terms of across-shelf transports the onshore bottom Ekman layer flows offset the offshore surface Ekman layer flows, allowing the sea surface slope to remain in quasi steady state while feeding an upwelling circulation. Owing to the geometries of both the coastline and the isobaths, the region offshore of Tampa Bay takes on a special significance. There we observe a confluence of flows (Figure 4) due to steering by the coastline and turning by the bottom Ekman layer. The result is a region of locally maximum upwelling (Figure 5). The transition between the alongshore coastal jet and the return flow also has an important bottom boundary layer manifestation. Within the return flow the bottom Ekman layer causes a down isobath component and hence a region of downwelling (Figure 5).

Other large vertical motion regions are also seen in Figure 5. The large across-isobath flows due to the strong, narrow coastal jet on the Panhandle coast result in large upwelling there. Both up and down isobath flows in the Big Bend region result in either upwelling or downwelling there. Similarly, in the southeastern corner of the model domain, where the flow steers offshore, there exists a complicated distribution of vertical velocity as water piles up and moves down isobath. Finally, the regular sequence of upwelling and downwelling found along the shelf break results from the bottom boundary layer interactions with the northwestward return flow. This is shown in Figure 6 for the near-bottom horizontal velocity component field at the shelf break. The across-isobath perturbations account for the sequence of upwelling and downwelling seen in Figure 5. These perturbations pervade the entire water column, as expected by the Taylor-Proudman theorem. They 


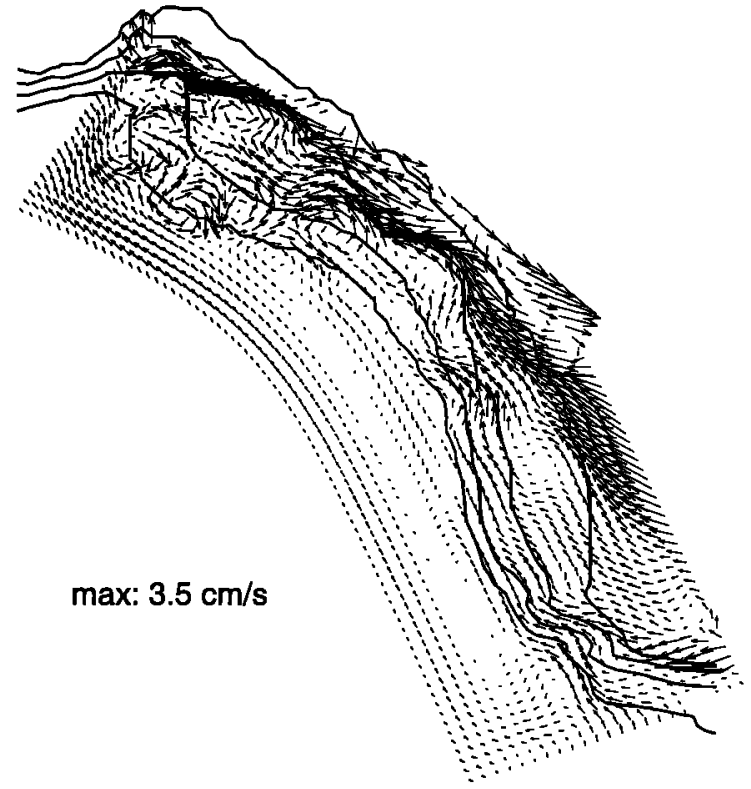

Figure 6. Horizontal velocity vector fields from the nearbottom shelf break region of Figure 4 with the 100, 200, 500, and $1000 \mathrm{~m}$ isobaths superposed as thick lines. Note the eddylike structures that are evident over the steep topography.

have a spatial scale of about $150 \mathrm{~km}$ and a propagation speed of about $30 \mathrm{~km} \mathrm{~d}^{-1}$. The spatial scale matches that of the eddies observed by Niiler [1976], and the speed is consistent with the dispersion relationship for topographic Rossby waves [e.g., Gill, 1982]. While Niiler [1976] attributed these pertur- bations to the Loop Current (explicitly excluded from our study), they may occur in response to any flows over such steep topography.

As these topographic waves approach the Desoto Canyon, their horizontal structure becomes more complicated because of topography, but their amplitude remains steady. The lack of growth with time for these wave perturbations in the northwest corner of the model domain provides evidence that the open boundary conditions (which contain no added dissipation) are working properly.

\subsection{Vertical Structure of the Flow Field}

Complementing the description on the evolution of the flow fields on sigma surfaces, Figure 7 shows across-shelf sections of the velocity components sampled on the west Florida coast off Sarasota on days 1,4 , and 8 . In the alongshore velocity component we see the southeastward coastal jet within the region of maximum sea surface deformation (Figure 3 ) and the subsequent development of the northwestward return beneath the surface Ekman layer farther offshore. As the coastal jet accelerates, a bottom Ekman layer develops, causing an onshoredirected across-shelf velocity component near the bottom. By virtue of the kinematic bottom boundary condition this results in upwelling, with maximum amplitude centered upon the region of maximum across-shelf flow. Similarly, downwelling occurs in the region of northwestward return flow. The result is a fully three-dimensional flow field.

Regional differences occur in the flow field structures because of the WFS geometry. This is evident in Figure 8, which compares across-shelf sections sampled at the Panhandle coast, the Big Bend, and the west Florida coast off Sarasota. They all show similar features, but with varying intensity and

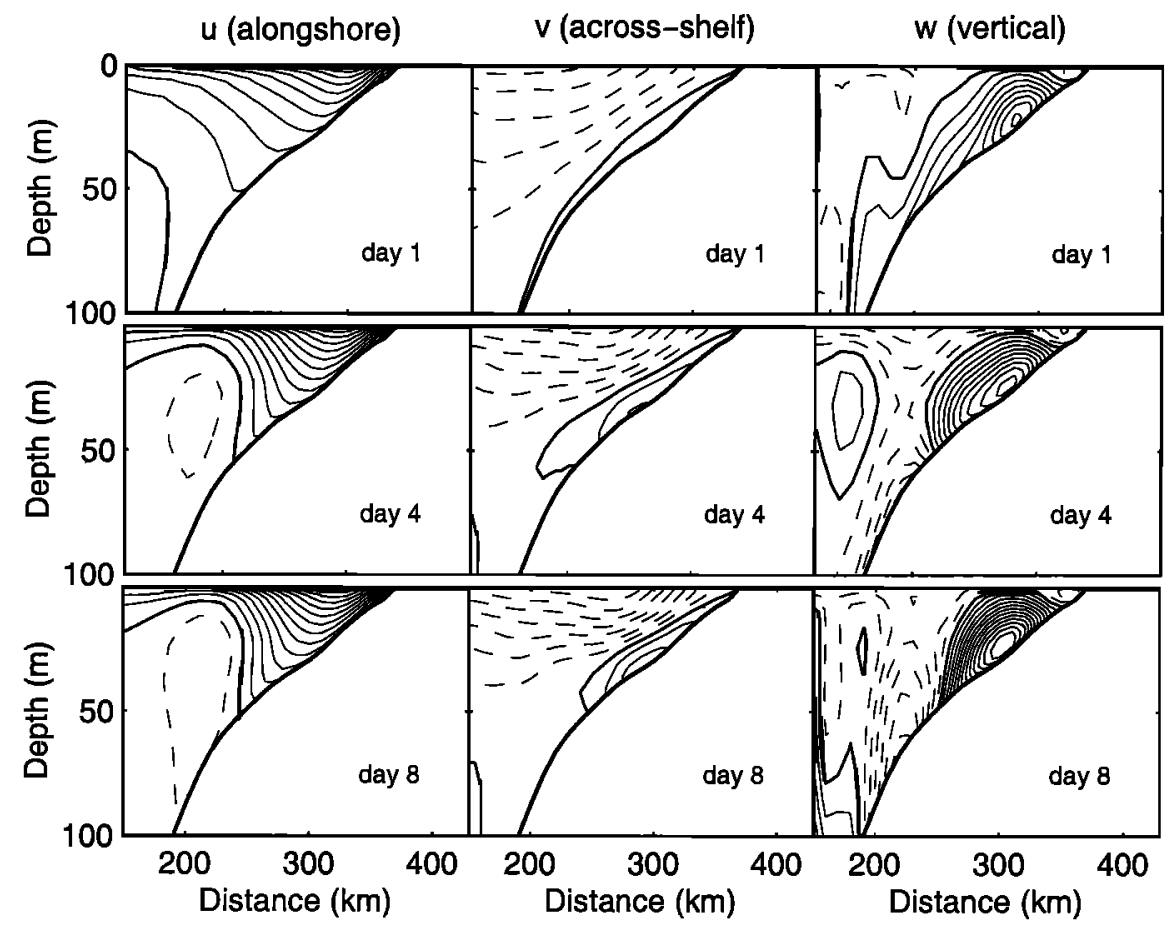

Figure 7. The structures of the three velocity components $(u, v$, and $w)$ at days 1,4 , and 8 for the alongshore wind experiment sampled at cross section III (see Figure 1). For $u$, $v$, and $w$, solid lines denote southeastward alongshore, onshore, and upwelling, respectively, and dashed lines denote northwestward alongshore, offshore, and downwelling, respectively. Thick lines denote the zero contour, and the contour intervals for $u, v$, and $w$ are $0.02,0.01$, and $10^{-6} \mathrm{~m} \mathrm{~s}^{-1}$, respectively. 


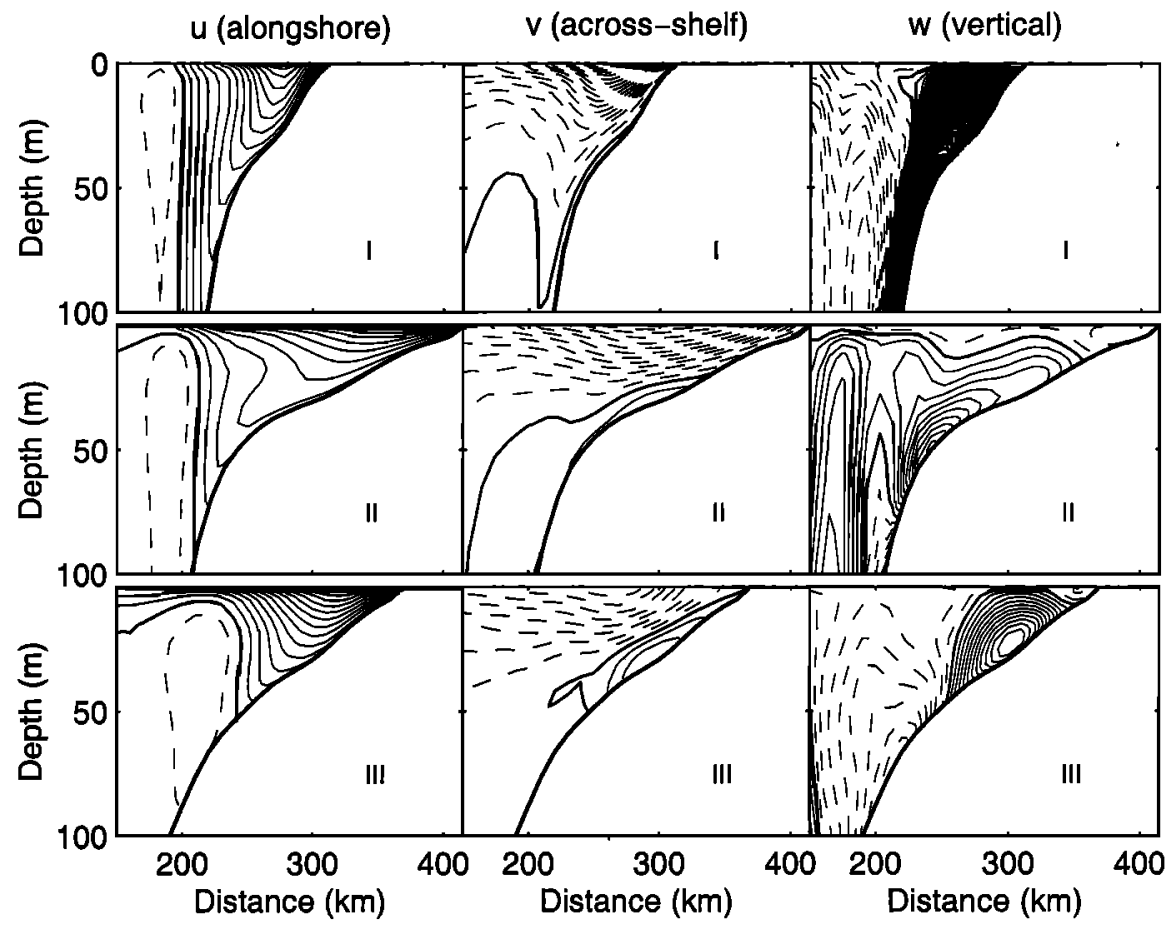

Figure 8. The structures of the three velocity components $(u, v$, and $w)$ at day 12 for the alongshore wind experiment sampled at cross sections I, II, and III (see Figure 1). For $u$, $v$, and $w$, solid lines denote southeastward alongshore, onshore, and upwelling, respectively, and dashed lines denote northwestward alongshore, offshore, and downwelling, respectively. Thick lines denote the zero contour, and the contour intervals for $u, v$, and $w$ are $0.02,0.01$, and $10^{-6} \mathrm{~m} \mathrm{~s}^{-1}$, respectively.

scale. Over the Big Bend region, where the isobath gradient is smallest, the offshore scale is largest, and the upwelling, while pervasive over the shelf, is of reduced amplitude relative to what is found to the north or south. Conversely, over the Panhandle, where the isobath gradient is largest, the offshore scale is smallest, and the upwelling is more intense and pene-
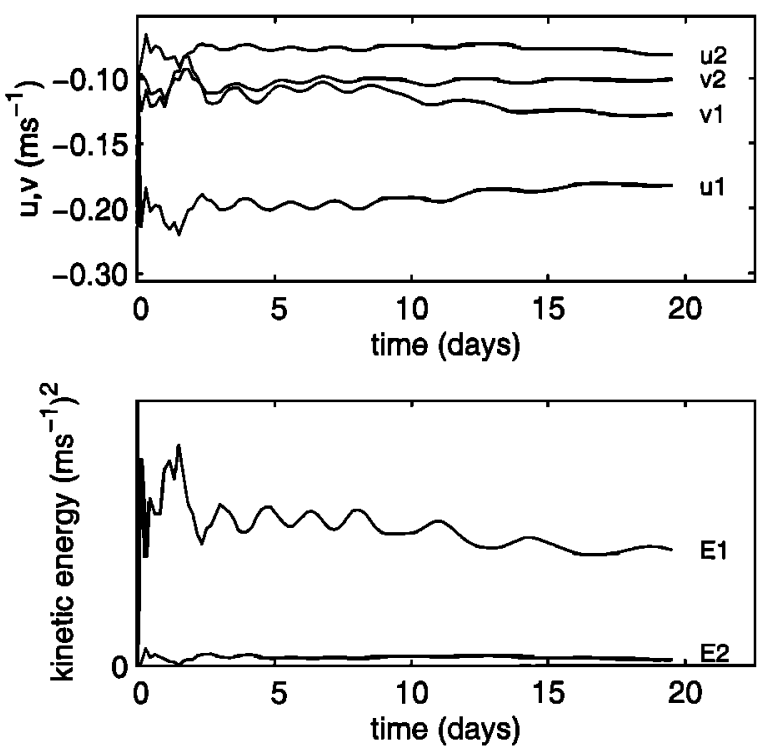

Figure 9. Kinetic energy and velocity component time series near the surface (1) and bottom (2) at $28^{\circ} \mathrm{N}, 84^{\circ} \mathrm{W}(1.31$ and $45.7 \mathrm{~m}$, respectively, at $47 \mathrm{~m}$ total depth) from the offshore wind experiment. trates to deeper depth. These basic differences can all be attributed to the intensity of the coastal jet and hence the acrossshelf transports bought about by the bottom Ekman layer.

\section{Offshore Wind Experiment}

This experiment investigates the response of the WFS to a wind stress that is rotated $90^{\circ}$ clockwise from the previous case. It has the same magnitude $\left(1 \mathrm{dyn} \mathrm{cm}^{-2}\right)$, and, directed $240^{\circ}$ with respect to true north, it is offshore with respect to the west Florida coast. As in the previous case, a constant, spatially uniform wind stress is applied as an initial value problem from a state of rest.

\subsection{Spin-Up and Sea Surface Elevation}

The model again spins up rapidly (Figure 9) by a classical Ekman response, redistributing mass and leading to a coastally confined surface deformation and an associated coastal jet. The shape of the coastline renders the overall response patterns for the surface deformation and the depth averaged currents (Figure 10) more complicated than for the alongshore wind-forced case. Jets set up along the Panhandle coast, the Big Bend, and the Florida Keys, where the winds tend to be alongshore. A jet-like structure and an associated sea level deformation then fill in along the west Florida coast, where the wind stress is directed offshore. The main features of this pattern are essentially in place after $\sim 2$ days, upon which the sea surface elevation contours nearly parallel the coastline over a large portion of the shelf, the set down is about half that of the alongshore wind-forced case over the west Florida coast, and the zero contour roughly coincides with the $40 \mathrm{~m}$ isobath. Within the Big Bend region, where both right and left hand 


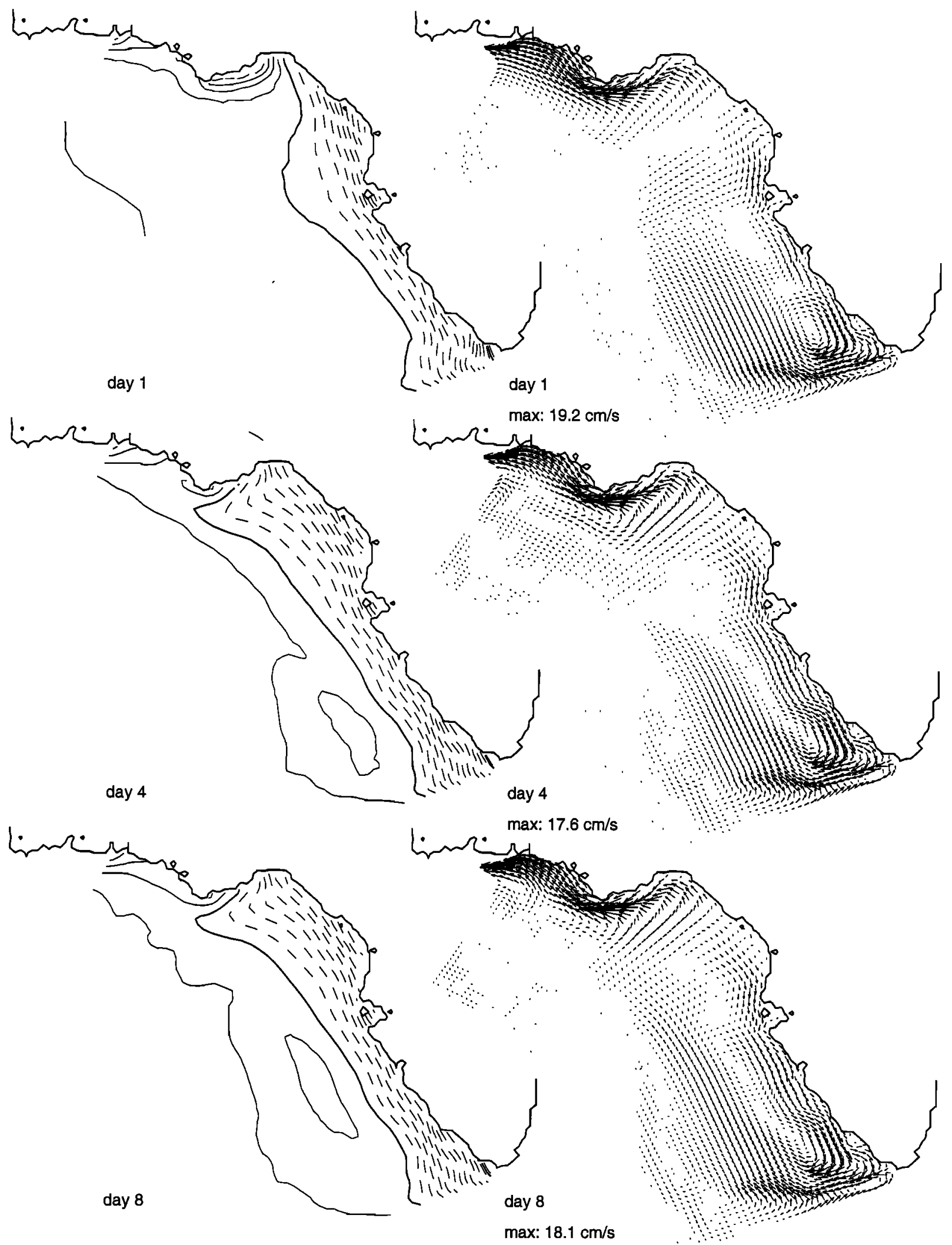

Figure 10. Sea surface elevation and depth-averaged velocity at days 1,4 , and 8 from the offshore wind experiment. For elevation, thick lines denote the zero contour, dashed lines are negative contours, and the contour interval is $0.01 \mathrm{~m}$. 


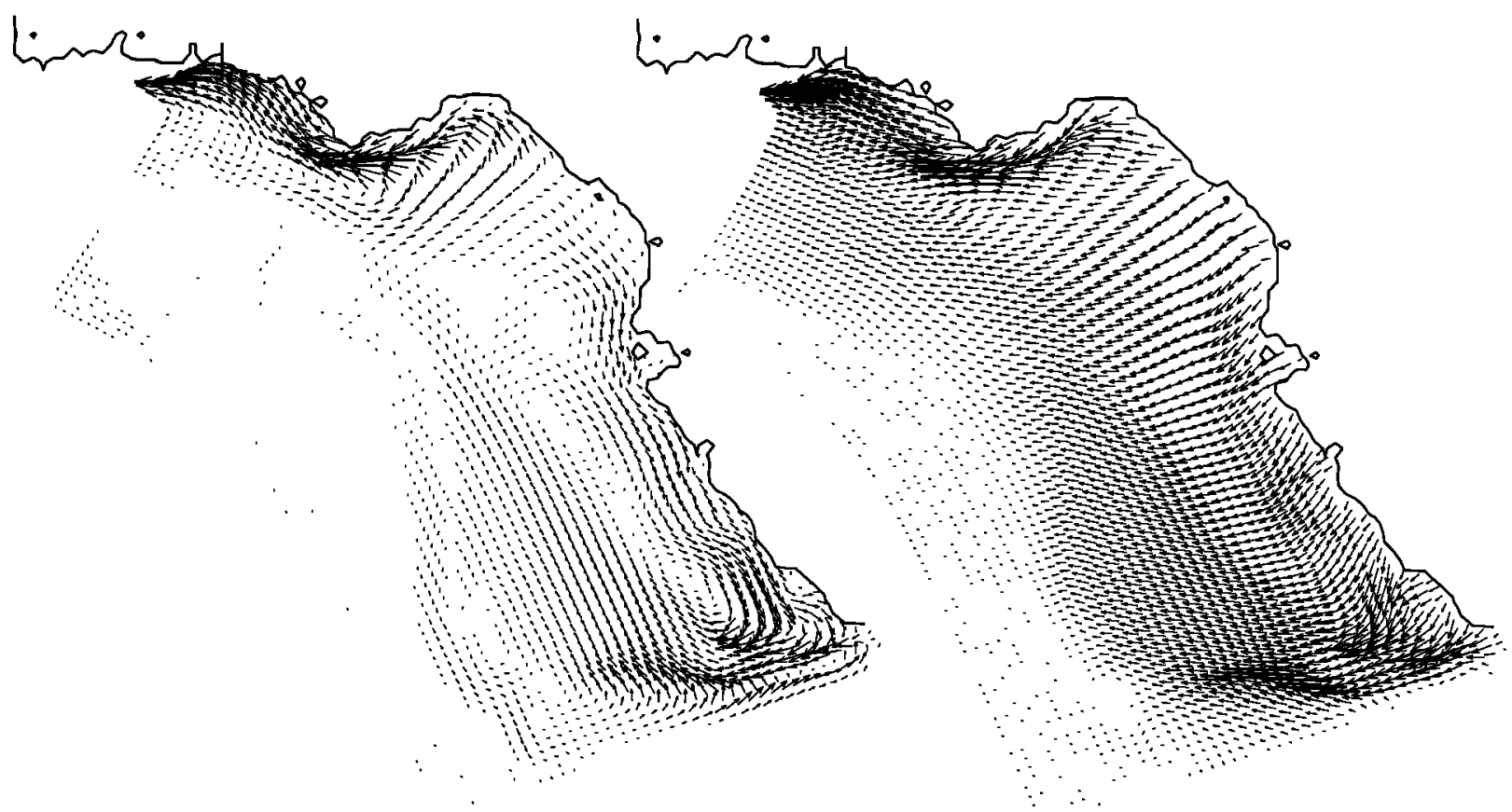

(a) depth-averaged (day 12). $\max : 17.1 \mathrm{~cm} / \mathrm{s}$

(b) subsurface (level 2, day 12). max: $29.1 \mathrm{~cm} / \mathrm{s}$

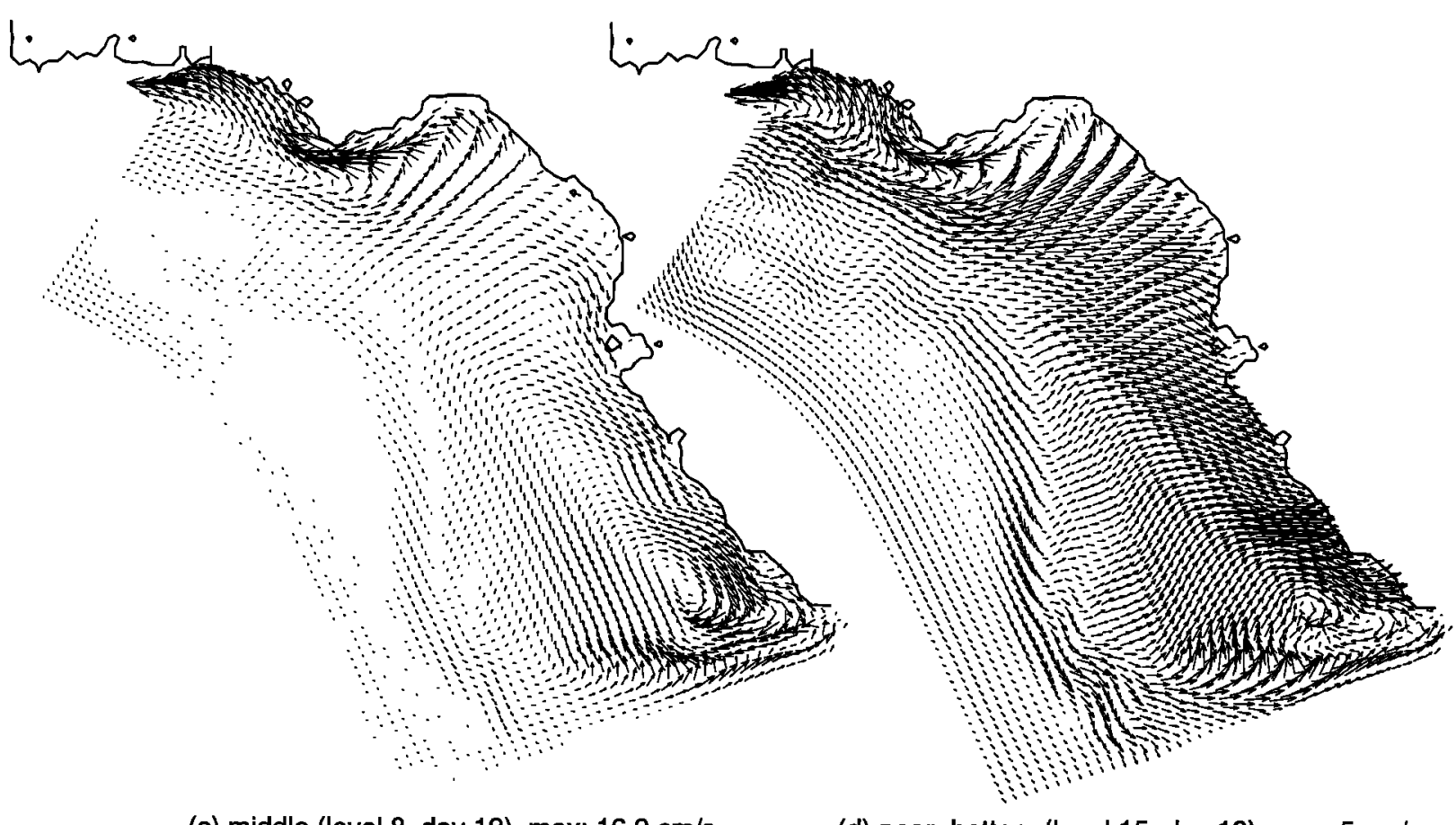

(c) middle (level 8 , day 12). $\max : 16.9 \mathrm{~cm} / \mathrm{s}$

(d) near-bottom (level 15, day 12). $\max : 5 \mathrm{~cm} / \mathrm{s}$

Figure 11. Horizontal velocity vector fields at day 12 for the offshore wind experiment: (a) depth-averaged, (b) near-surface (sigma level 2), (c) middepth (sigma level 8), and (d) near-bottom (sigma level 15).

coastlines exist relative to the winds, a bifurcation results in the flow field. As is the case for the alongshore winds, return flows farther offshore take longer to establish.

\subsection{Flow Field on Sigma Surfaces}

Horizontal velocity field maps sampled on day 12 for the depth average (Figure 11a), the near-surface level 2 (Figure 11b), the middle level 8 (Figure 11c), and the near-bottom level 15 (Figure 11d) are shown in Figure 11. The depthaveraged and middepth currents are very similar. Compared with the alongshore wind-forced experiment, a relatively weak and spatially inhomogeneous southeastward alongshore jet appears along the west Florida coast closed by an offshore northwestward return flow originating in the south because of the 


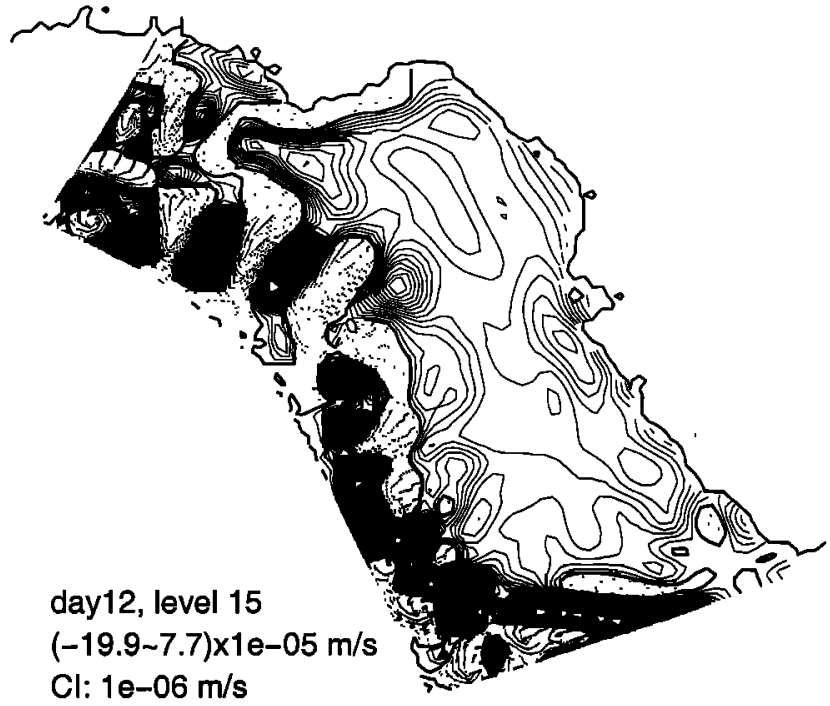

Figure 12. Vertical velocity component field at day 12 for the offshore wind experiment, sampled near the bottom (at sigma level 15) and transformed to the $z$ coordinate of a standard rectilinear $x, y, z$ system. Solid lines denote upwelling, dotted lines denote downwelling, and the contour interval is $10^{-6} \mathrm{~m}$ $\mathrm{s}^{-1}$.

partially closed boundary there. The bifurcation in the Big Bend region feeds a northwestward coastal jet consistent with the change in sea surface topography over the Panhandle coast. These added spatial inhomogeneities make the overall flow patterns for the offshore wind case more complicated than for the alongshore wind case. Instead of one overall coastal jet and offshore return flow regime, there are now two gyre-like systems over the northern and southern portions of the model domain, separated by the Big Bend region. This double-gyre system is qualitatively consistent with the observational inference of Chew [1955]. These overall patterns are consequences of the coastline geometry, including the partial closure of the southern boundary by the Florida Keys.

The near-surface and near-bottom flow fields provide the across-shelf mass transports necessary to set up the surface pressure field and to maintain the fully three-dimensional nature of the quasi steady state circulation. Within the nearshore region the surface flow field is generally directed offshore, gradually turning to the right to become a pure Ekman layer flow outside the region of pressure gradient influence. The bifurcation in the Big Bend is quite evident with the nearsurface flow in the center of the Big Bend being directed offshore and turning to the left and the right to form coastal jets to the south and north, respectively. Offshore-directed flow is also seen at the southern boundary although there it is ageostrophic since it must flow in opposition to the pressure gradient. The near-bottom flow field generally shows onshoredirected currents. These also bifurcate within the Big Bend, feeding the respective coastal jets. Just offshore from the Big Bend, however, there is a pattern of near-bottom return flow originating from the Panhandle coast that is continuous with the west Florida coast. The surface and bottom boundary layer responses to this offshore wind stress experiment thus provide for across-shelf transports over the entire extent of the continental shelf.

The across-shelf component of flow near the bottom results in the near-bottom vertical velocity component distribution shown in Figure 12. Upwelling is generally seen over the entire shelf domain with the exception of the transitional coastal jet region from the Big Bend to the Panhandle coasts, where the sea level elevation is relatively high and near-bottom flow is directed down isobath near the coast. Of particular interest is the region of maximum upwelling just offshore and to the south of Tampa Bay. This is supported by observations, as will be discussed. Similar to the alongshore wind-forced experiment, a regularly occurring sequence of upwelling and downwelling is seen along the regions of the shelf break and the Desoto Canyon.

\subsection{Vertical Structure of the Flow Field}

Across-shelf sections of the velocity components sampled on the west Florida coast off Sarasota on days 1, 4, and 8 are shown in Figure 13. A southeastward coastal jet develops in the alongshore velocity component, but it is relatively weak and more coastally confined than in the alongshore wind-forced experiment. The return flow farther offshore is also weaker, and it is a combination of Ekman and pressure gradient flow, as contrasted with a distinctive subsurface countercurrent flowing in opposition to the surface Ekman flow. Turning in the bottom Ekman layer beneath the alongshore coastal jet produces an onshore-directed near-bottom flow in the across-shelf component that tends to compensate the offshore-directed near surface flow. This results in upwelling over the entire section out to the shelf break, with maximum values on about the $20 \mathrm{~m}$ isobath, where the coastal jet is largest. As in the previous case, the flow field is fully three-dimensional and horizontally divergent even for these relatively simple, constant density experiments.

Regional differences in the across-shelf structure are again evident in the Figure 14 comparison of across-shelf sections sampled on the Panhandle coast, the Big Bend, and the west Florida coast off Sarasota. As with the alongshore wind-forced experiment, they all show similar features, but with varying intensity and scale. An oppositely directed coastal jet with subsurface countercurrent distinguishes the Panhandle coast section from those farther south. This confines the upwelling in the Panhandle region to the vicinity of the coast, as contrasted with upwelling over a broader shelf domain farther south. These findings of spatial nonhomogeneity further highlight the importance of the coastline and isobath geometries for the WFS circulation. Depending upon wind direction and location along the coast, these experiments suggest that the across-shelf transports may facilitate a communication of waters between the shelf-break and the coastal zone.

\section{Other Experiments}

While the focus of this paper is on upwelling favorable wind-forced responses, we also performed a companion set of experiments for the cases of downwelling favorable winds directed either alongshore toward the northwest or onshore. The wind stress magnitudes are the same, only the directions are reversed. For completeness, the horizontal velocity fields on different sigma levels for these downwelling favorable alongshore and onshore winds are shown in Figures 15 and 16, respectively. By comparing Figures 15 and 4, or Figures 16 and 11 , it is found that equal but oppositely directed winds yield nearly equal but oppositely directed currents (or surface slopes) under a barotropic setting. 


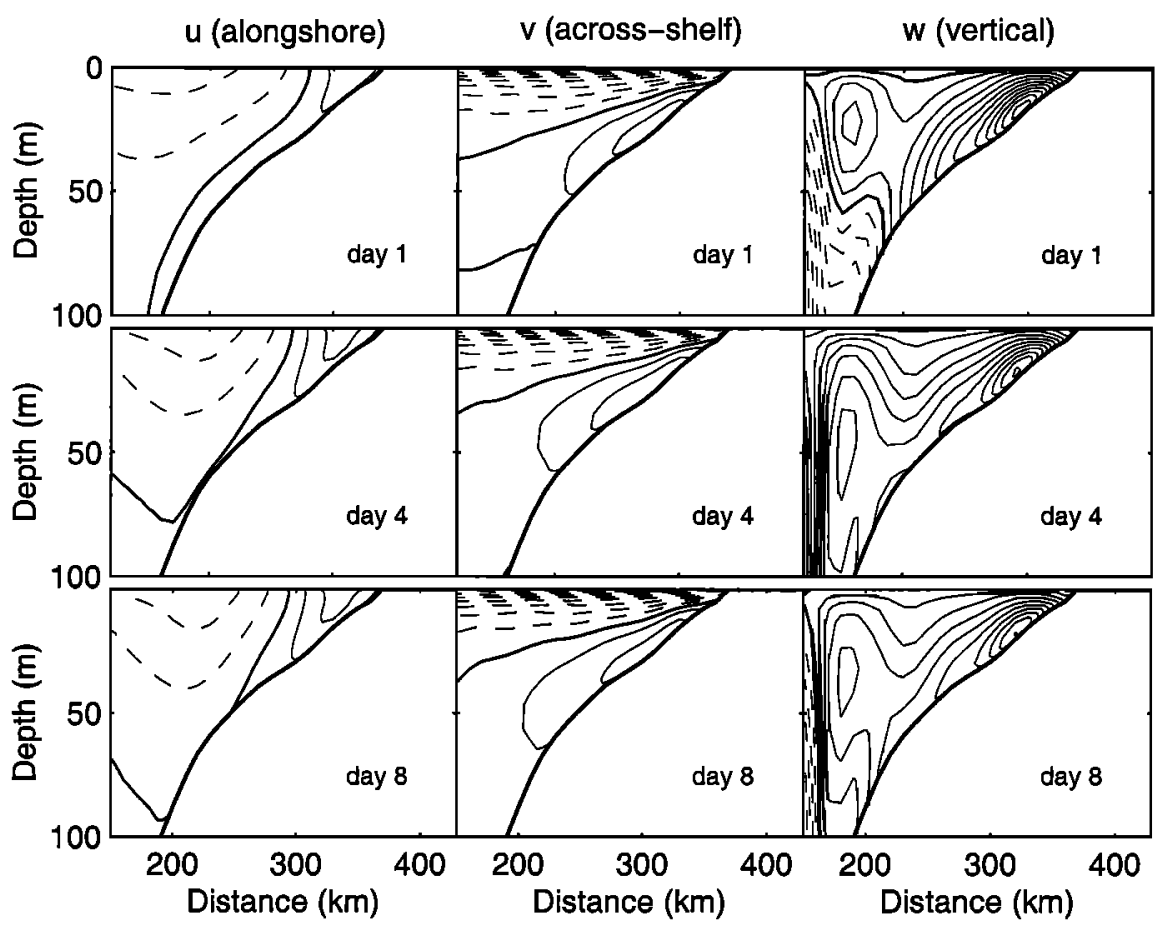

Figure 13. The structures of the three velocity components $(u, v$, and $w)$ at days 1,4 , and 8 for the offshore wind experiment sampled at cross section III (see Figure 1). For $u$, $v$, and $w$, solid lines denote southeastward alongshore, onshore, and upwelling, respectively, and dashed lines denote northwestward alongshore, offshore, and downwelling, respectively. Thick lines denote the zero contour, and the contour intervals for $u, v$, and $w$ are $0.02,0.01$, and $10^{-6} \mathrm{~m} \mathrm{~s}^{-1}$, respectively.

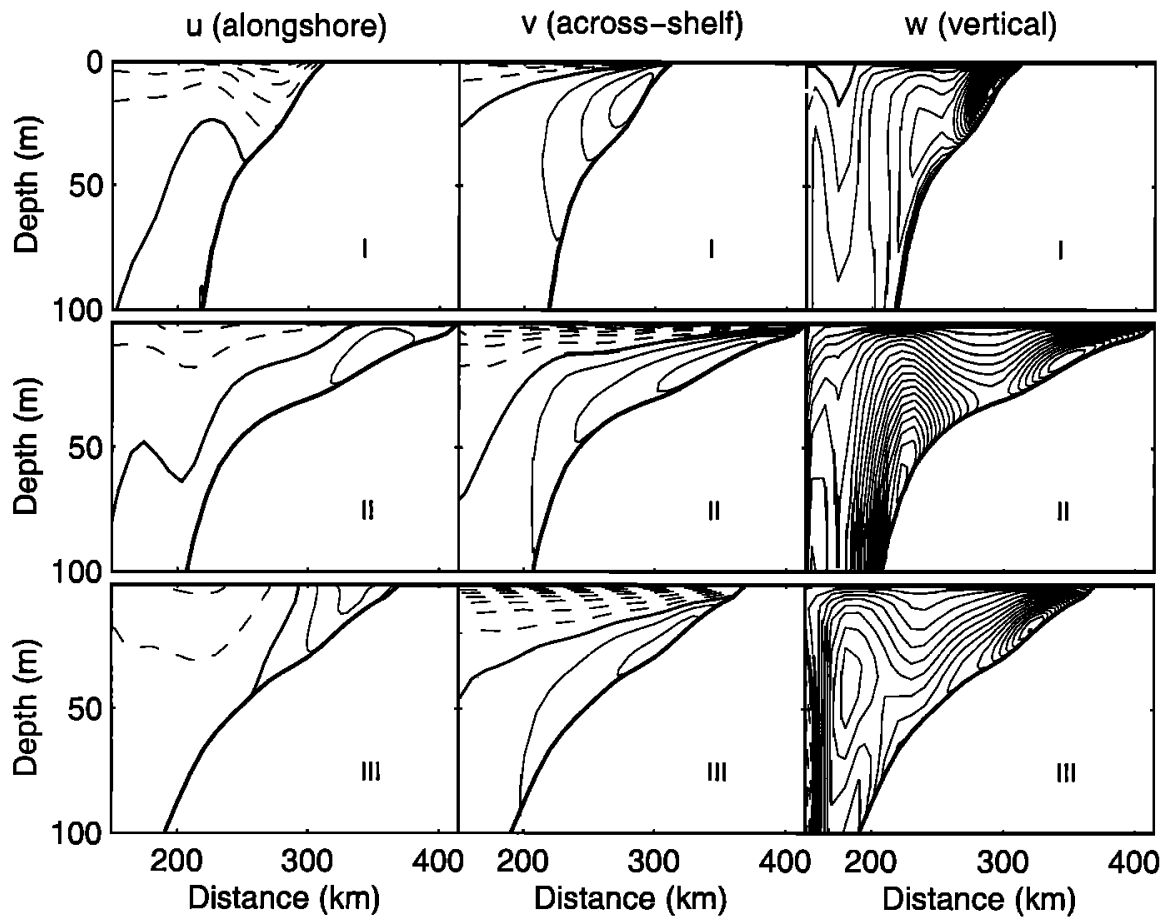

Figure 14. The structures of the three velocity components $(u, v$, and $w)$ at day 12 for the offshore wind experiment sampled at cross sections I, II, and III (see Figure 1). For $u, v$, and $w$, solid lines denote southeastward alongshore, onshore, and upwelling, respectively, and dashed lines denote northwestward alongshore, offshore, and downwelling, respectively. Thick lines denote the zero contour, and the contour intervals for $u, v$, and $w$ are $0.02,0.01$, and $10^{-6} \mathrm{~m} \mathrm{~s}^{-1}$, respectively. 


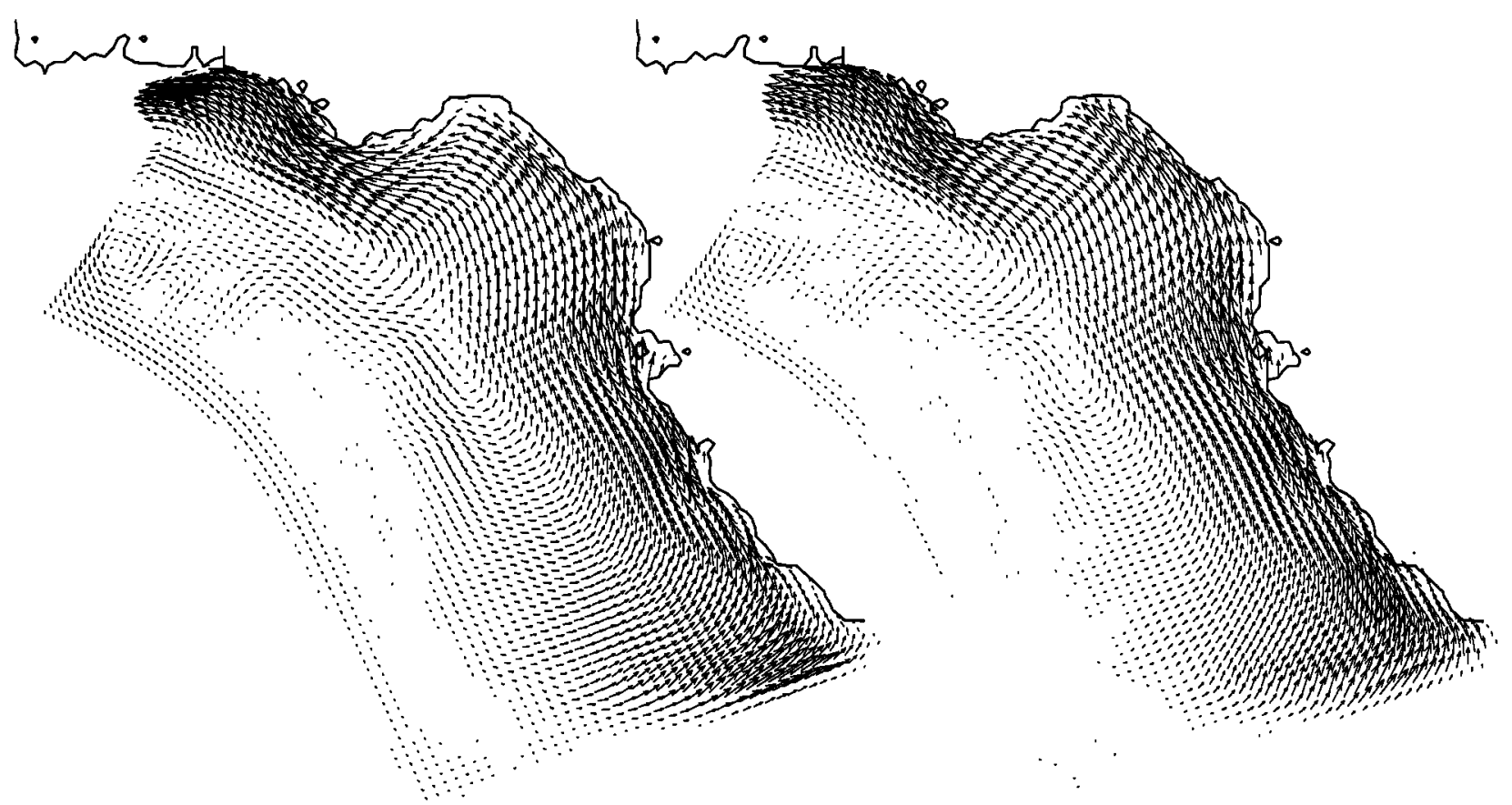

(a) depth-averaged (day 10). max: $18.4 \mathrm{~cm} / \mathrm{s}$

(b) subsurface (level 2, day 10). max: $26.1 \mathrm{~cm} / \mathrm{s}$

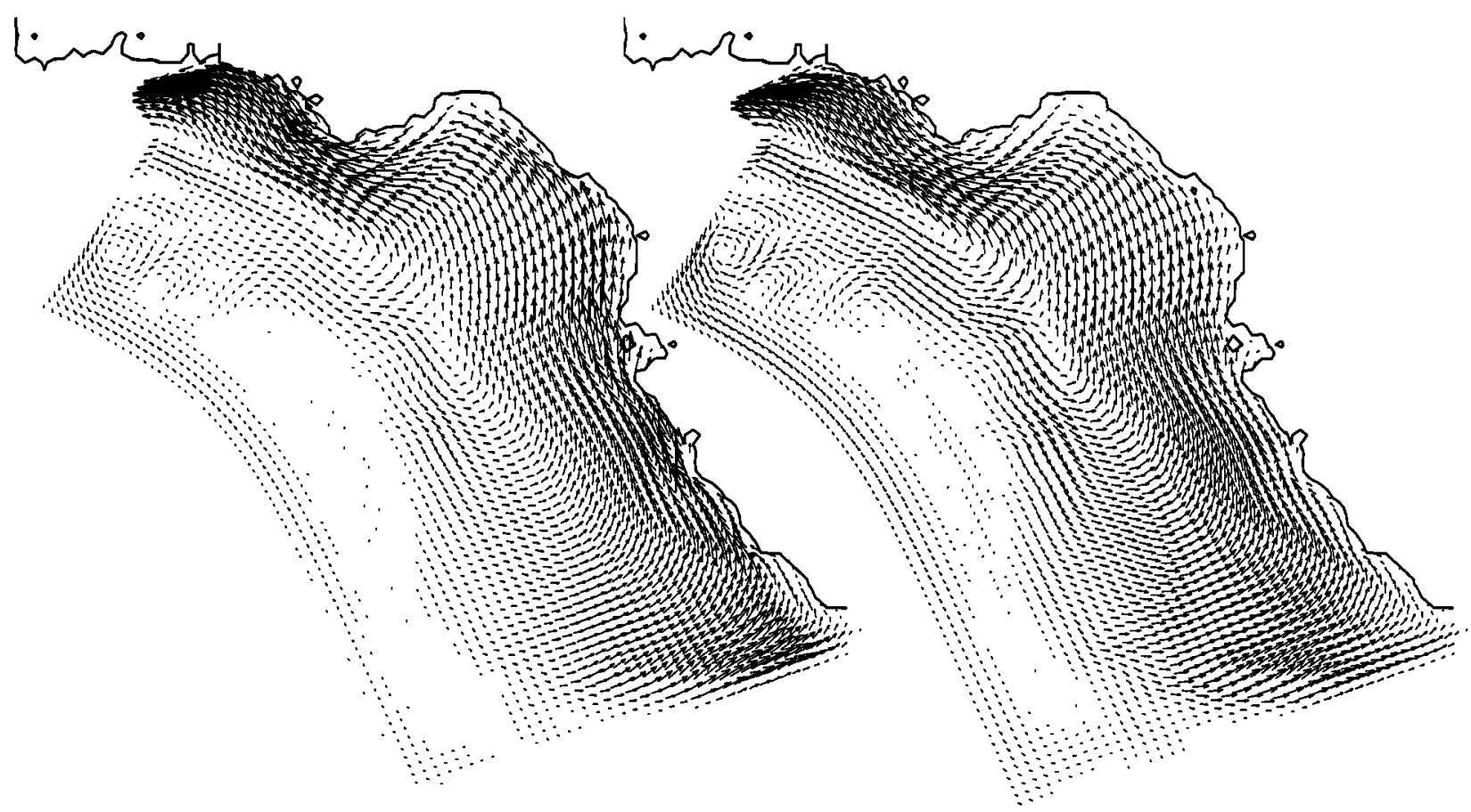

(c) middle (level 8, day 10). max: $18.5 \mathrm{~cm} / \mathrm{s}$

(d) near-bottom (level 15, day 10). max: $10.3 \mathrm{~cm} / \mathrm{s}$

Figure 15. Horizontal velocity vector fields at day 12 for the northwestward alongshore wind experiment: (a) depth-averaged, (b) near-surface (sigma level 2), (c) middepth (sigma level 8), and (d) near-bottom (sigma level 15).

To facilitate a better understanding of the model behavior, six sensitivity experiments, as summarized in Table 3 , are also presented (fashioned after Allen et al. [1995]). The first four investigate the model dependence upon the vertical eddy coefficient parameterization. The other two examine the model dependence on wind stress magnitude. Two sets of comparisons are given. The first shows snapshots of the fields of surface elevation and depth-averaged currents for the six sensitivity experiments (Figures 17a and 17b), each performed using an offshore-directed wind stress as in section 4 . The second shows 


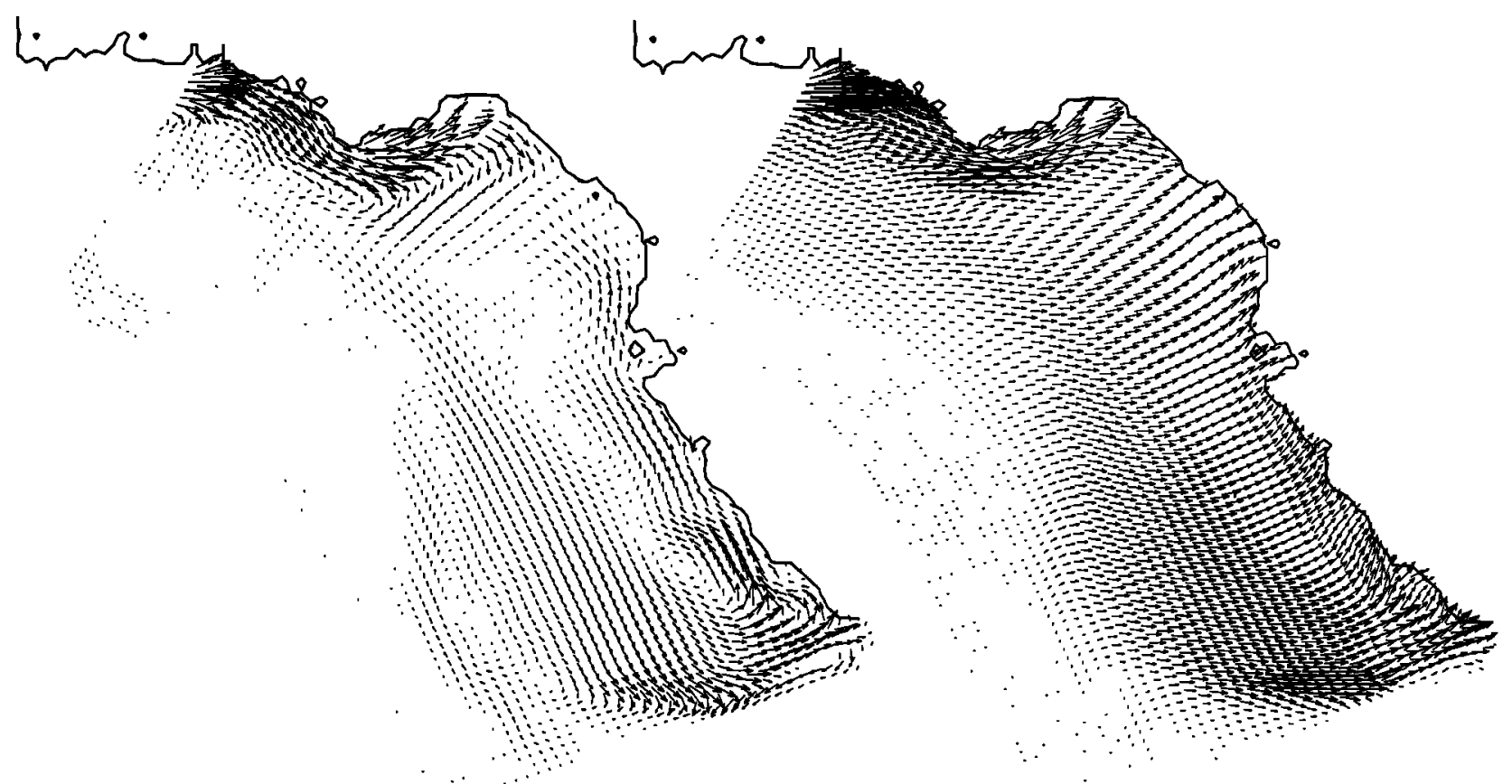

(a) depth-averaged (day 12). $\max : 17.3 \mathrm{~cm} / \mathrm{s}$

(b) subsurface (level 2, day 12). $\max : 29 \mathrm{~cm} / \mathrm{s}$

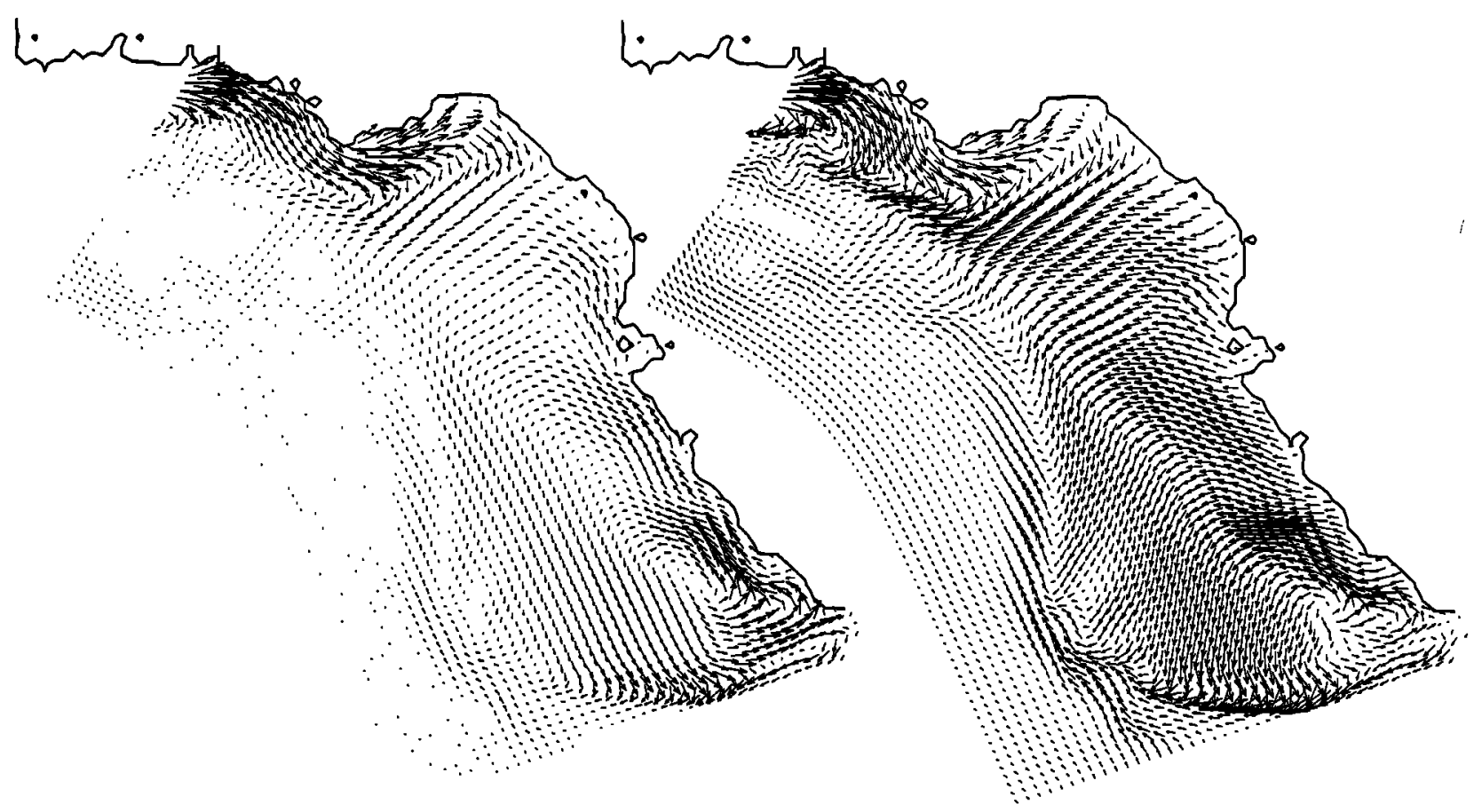

(c) middle (level 8, day 12). max: $17.1 \mathrm{~cm} / \mathrm{s}$

(d) near-bottom (level 15, day 12). $\max : 5.6 \mathrm{~cm} / \mathrm{s}$

Figure 16. Horizontal velocity vector fields at day 12 for the onshore wind experiment: (a) depth-averaged, (b) near-surface (sigma level 2), (c) middepth (sigma level 8), and (d) near-bottom (sigma level 15).

the vertical structures for the horizontal velocity components sampled in the across-shelf section off Sarasota (Figure 18). For the turbulence closure experiments we replaced the default closure scheme with constant eddy coefficients, and for the wind stress magnitude experiments we either halved or doubled the stress magnitude. Thus, from top to bottom in
Figures $17 \mathrm{a}, 17 \mathrm{~b}$, and 18 the first four panels give results for constant eddy coefficients of magnitude: $0.05,0.005,0.0005$, and $0.0005 \mathrm{~m}^{2} \mathrm{~s}^{-1}$ plus the standard turbulence closure model. The bottom two panels give the standard turbulence closure model results, but with winds of magnitude 0.5 and $2 \mathrm{dyn}^{-2}$. Regardless of the vertical eddy coefficient choice, the basic 
Table 3. Summary of the Additional Numerical Experiments Designed to Test the Dependence of the Model on the Parameterization of the Turbulent Eddy Coefficient and on the Magnitude of the Applied Offshore Wind Stress

\begin{tabular}{lcc}
\hline & \multicolumn{2}{c}{ Description } \\
\cline { 2 - 3 } \multicolumn{1}{c}{ Experiment } & $\tau$, dyn cm & $K_{m}$ \\
\hline$K_{m}: 0.05$ & 1 & $0.05 \mathrm{~m}^{2} \mathrm{~s}^{-1}$ \\
$K_{m}: 0.005$ & 1 & $0.005 \mathrm{~m}^{2} \mathrm{~s}^{-1}$ \\
$K_{m}: 0.0005$ & 1 & $0.0005 \mathrm{~m}^{2} \mathrm{~s}^{-1}$ \\
$K_{m}:$ pom +0.0005 & 1 & pom $+0.0005 \mathrm{~m}^{2} \mathrm{~s}^{-1}$ \\
$K_{m}:$ half wind & 0.5 & pom \\
$K_{m}:$ double wind & 2 & pom \\
\hline
\end{tabular}

Here pom denotes vertical eddy coefficient from the turbulence closure submodel of the Princeton Ocean Model (POM).

patterns for the sea surface elevation and depth-averaged currents are similar, although the magnitude of the currents varies, as does the across-shelf scale. Similarly, by varying the magnitude of the wind stress, the magnitude of the response varies, but not the overall response patterns.

Unlike the vertically integrated quantities, the vertical structure of the flow field is sensitive to the vertical eddy coefficient because stress is the product of the eddy coefficient and the vertical shear. Decreasing the vertical eddy coefficient increases the vertical shear, thereby strongly affecting the character of the flow. Since the currents over the lower portion of the water column are set by the pressure gradient force (which is relatively insensitive to eddy coefficient), a small vertical eddy coefficient results in a surface-confined response with unrealistically large vertical shears. Only in the cases that include the turbulence submodel or use an unrealistically large constant eddy coefficient do currents with similar magnitudes penetrate the entire water column as observed (e.g., Weisberg et al., 1996b]. With the standard turbulence submodel the wind stress magnitude sensitivity experiments give results that are approximately linearly proportional.

All experiments included latitudinally varying Coriolis parameter. Not shown is an experiment performed with constant Coriolis parameter. This eliminated some of the eddy-like features observed in the previous horizontal pattern maps, suggesting that the planetary $\beta$ effect is a factor along with the topographic $\beta$ effect in regions other than the shelf break. However, omitting the planetary $\beta$ effect does not affect the overall flow fields.

\section{Summary}

Investigation is made into the circulation and sea level responses of the west Florida continental shelf to upwelling favorable southeastward alongshore and offshore wind stresses, using the three-dimensional, primitive equation POM under a barotropic setting. In each case an initial value problem is solved from a state of rest. The surface elevation and currents evolve rapidly to quasi steady states by route of the classical Ekman-geostrophic responses to wind forcing. The redistribution of mass, initially in the surface boundary layer, causes the sea level to slope, driving a geostrophic interior flow and a bottom boundary layer response. Opposing transports in the surface and bottom Ekman layers then maintain the quasi steady state. The geometries of the coastline and the isobaths, including the partial closure of the southern boundary by the
Florida Keys and changes in coastline orientation within the Big Bend region and the Panhandle coast, are found to have large impacts upon the responses.

Alongshore forcing produces a broad continuous coastal jet and a subsurface return flow seaward of the jet. This return flow originates in the southeastern corner of the model domain, where water must flow ageostrophically up pressure gradient because of the partial boundary closure by the Florida Keys. The coastal jet is strongest where the shelf is narrowest (along the Panhandle coast and south of Tampa Bay), conforming to the surface elevation gradient. Regions of strongest flows have the largest bottom Ekman layer transports, thereby setting the regions of locally maximum upwelling. Large upwelling is therefore identified along the escarpment south of Apalachicola Bay on the Panhandle coast and offshore from Tampa Bay along the west Florida coast.

Offshore forcing produces narrower and weaker coastal jets of opposite sign to the north and south of the Big Bend region and with associated return flows farther offshore, this being a consequence of the specific regional geometry. These jets again determine the bottom Ekman layer transports and hence the regions of maximum upwelling. Upwelling is identified over almost the entire expanse of the WFS with a regional maximum just south of Tampa Bay.

Sensitivity experiments on the parameterization of vertical friction are performed by substituting the turbulence closure submodel of the POM with different values of constant eddy coefficients. While the overall spatial patterns for sea level and depth-averaged currents are not largely affected (the acrossshelf scale changes with the turbulence level), the vertical structure of the flow field is sensitive to the choice of vertical eddy friction parameterization. The turbulence submodel parameterization appears to give more realistic results (compared with limited in situ data) than a constant eddy coefficient parameterization. Other sensitivity experiments on the effect of wind stress magnitude show nearly linearly proportional results, and the sensitivity to the planetary $\beta$ effect is minor.

The principal conveyances of across-shelf transport that maintain either upwelling or downwelling circulations are the surface and bottom Ekman layers. A possible exception involves the topographic Rossby waves that appear along the shelf break as a regular sequence of upwelling and downwelling. These eddy-like features may be a factor in mixing and exchange of material and momentum between the shelf and the deep ocean, particularly over the Panhandle coast near Desoto Canyon, where the shelf is very narrow. Although the data are limited, observational support exists for the role of the surface and bottom Ekman layers. The region south of Apalachicola Bay has been identified as one of high primary productivity [Gilbes et al., 1996], and this coincides with a region of large model upwelling response to alongshore wind forcing. Over a year-long period, February 1996 to February 1997, in which satellite-tracked surface drifters were deployed offshore from the Big Bend and Panhandle coasts (P. Niiler, W. Sturges, and W. Johnson, personal communication, 1997), there were no instances of drifters entering the near-shore region south of Tampa Bay. Instead, all of the drifters that went south moved progressively farther offshore, indicative of a pervasive surface divergence and upwelling [Yang et al., 1999]. Satellite sea surface temperature imagery, in situ measurements of sea level and currents, and a numerical model simulation of a specific upwelling event (R. H. Weisberg et al., manuscript in preparation, 1999) confirm both the region of 


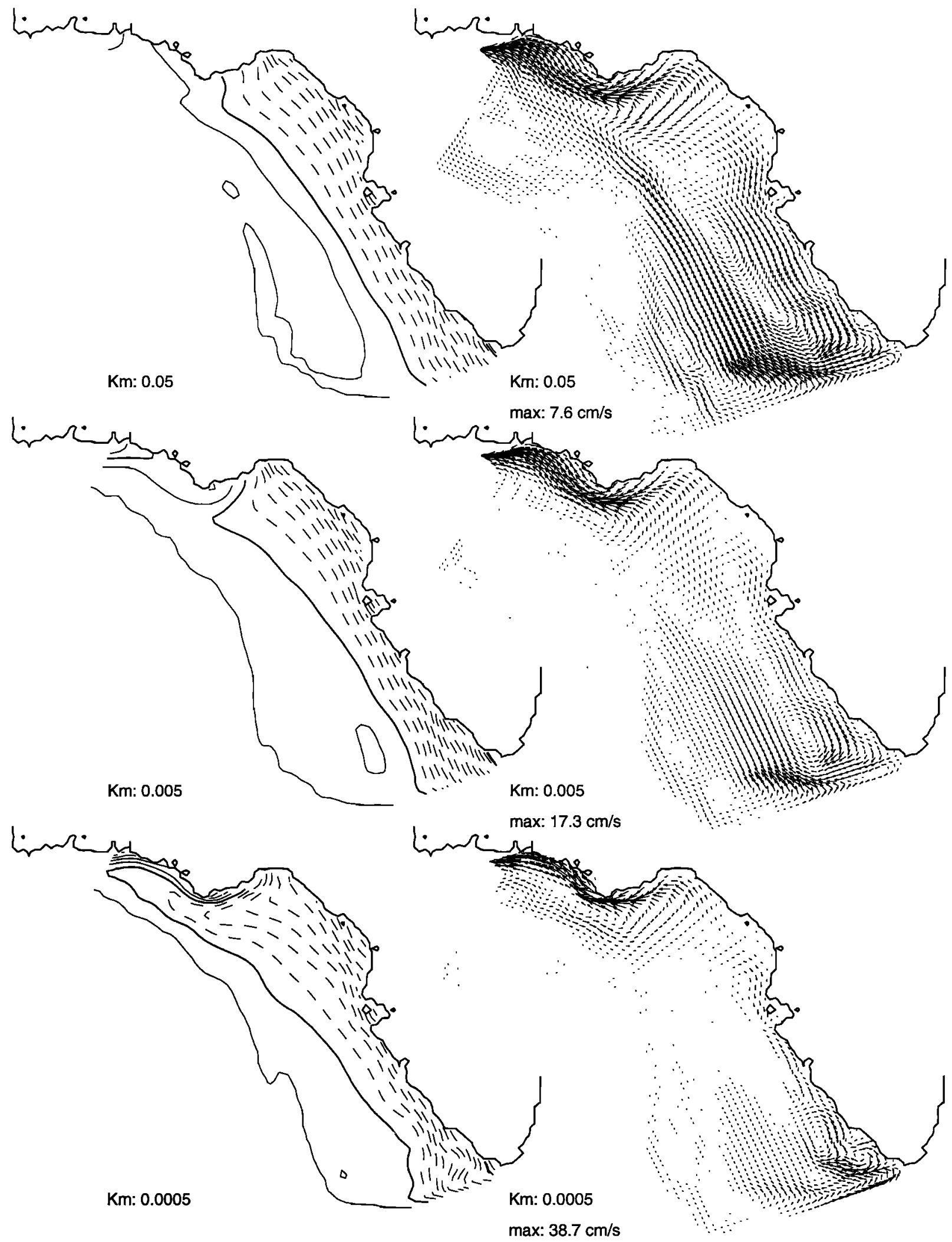

Figure 17a. Sea surface elevation and depth-averaged velocity vector fields at day 12 from the sensitivity experiments performed for offshore wind forcing. For sea level the thick line is the zero contour, dashed lines are negative contours, and the contour interval is $0.01 \mathrm{~m}$. From top to bottom results for constant vertical eddy friction coefficients of $0.05,0.005$, and $0.0005 \mathrm{~m}^{2} \mathrm{~s}^{-1}$, respectively, are displayed. 


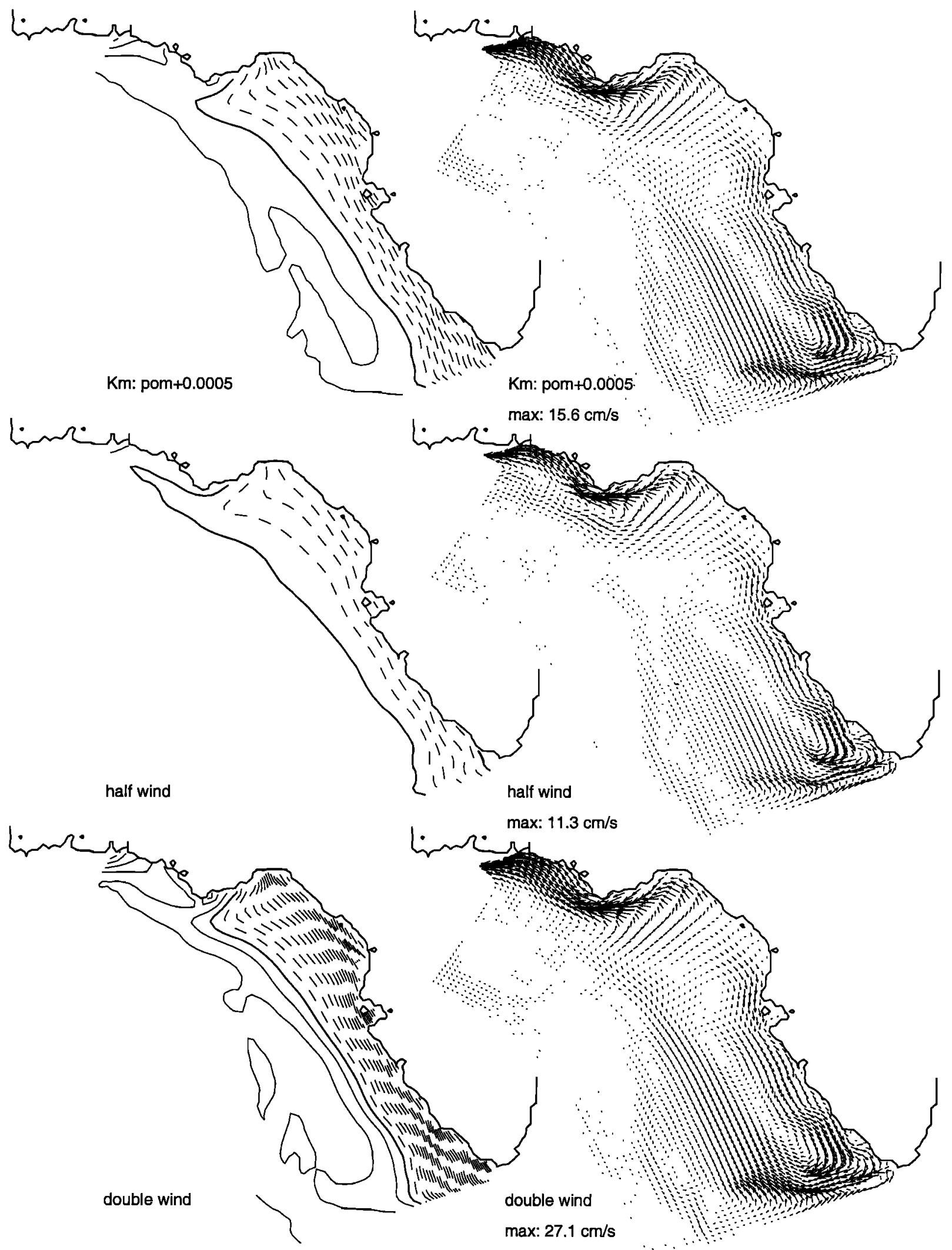

Figure 17b. Sea surface elevation and depth-averaged velocity vector fields at day 12 from the sensitivity experiments performed for offshore wind forcing. For sea level the thick line is the zero contour, dashed lines are negative contours, and the contour interval is $0.01 \mathrm{~m}$. From top to bottom are displayed the level 2.5 turbulence closure model with a minimum eddy coefficient magnitude of $0.0005 \mathrm{~m}^{2} \mathrm{~s}^{-1}$, the standard Princeton Ocean Model (POM) model, but with wind stress magnitude of $0.05 \mathrm{Nm}^{-2}$ (half the value of our previous analysis), and the standard POM model, but with wind stress magnitude of $0.2 \mathrm{Nm}^{-2}$ (twice the value of our previous analysis). 


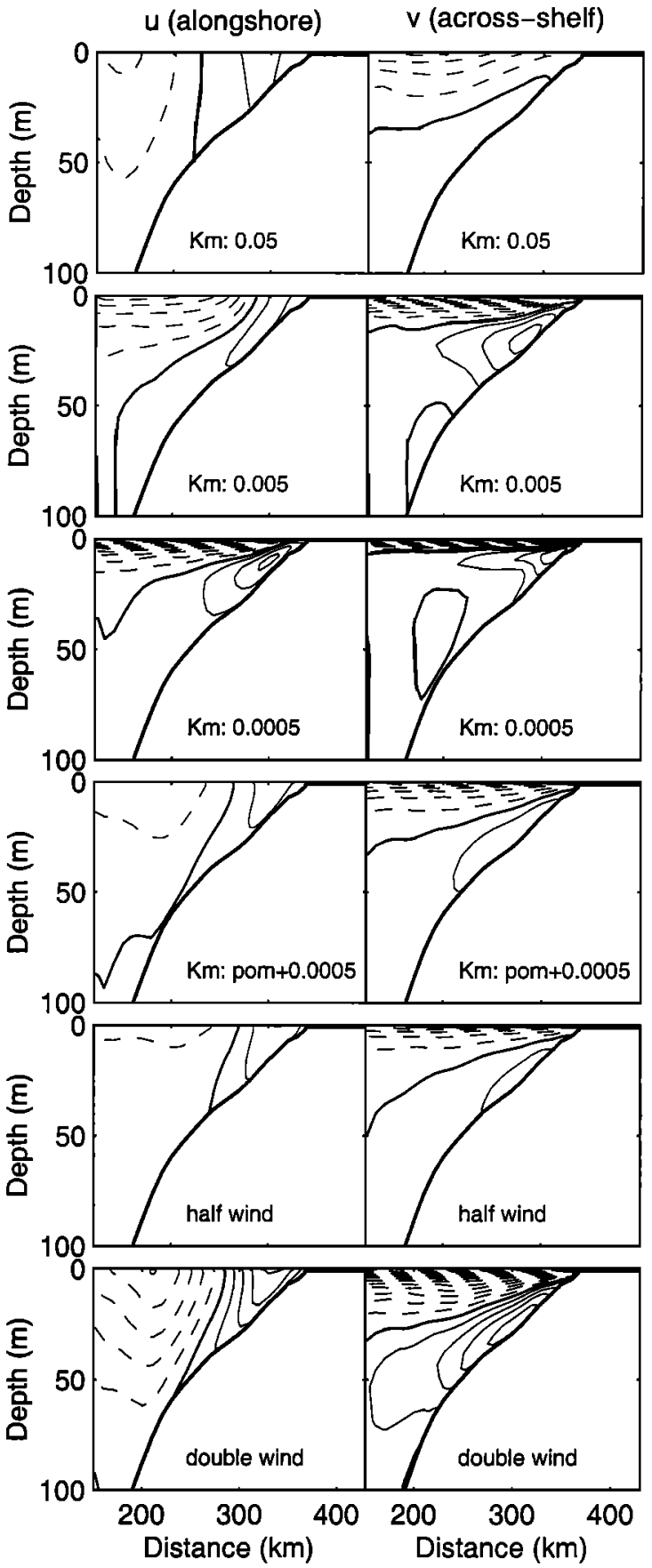

Figure 18. The structures of the horizontal $(u, v)$ velocity components at day 12 for the offshore wind-forcing sensitivity experiments sampled at cross section III (see Figure 1). Solid lines for $u$ and $v$ denote southeastward alongshore and onshore flow, respectively, and dashed lines denote northwestward alongshore and offshore flow, respectively. Thick lines denote the zero contour, and the contour intervals for $u$ and $v$ are 0.02 and $0.01 \mathrm{~m} \mathrm{~s}^{-1}$, respectively.

local maximum upwelling identified south of Tampa Bay and the rapid Ekman-geostrophic route to spin-up. For the effects of the offshore component of wind stress, Black [1998] shows that while the alongshore component of wind stress exhibits maximum coherence with west Florida coast sea level (similar to the findings of Marmorino [1982] and Cragg et al. [1983]), the wind direction that produces the largest magnitude sea level response includes both the alongshore and the across-shelf components. Weatherly and Thistle [1997] show bottom Ekman layer evidence in the Big Bend region. Recently acquired velocity data from the inner-shelf along the West Florida Coast [Siegel, 1999; R. H. Weisberg and E. Siegel, manuscript in preparation, 1999] demonstrate turning within the surface and bottom layers relative to the interior flow, partially offsetting across-shelf transports that are coherent with the sea level variations, and the associated evolution of coastal jets. These jets evolve on the timescale of the synoptic weather variations, and they appear to be fully three-dimensional with downstream acceleration/deceleration implied by net across-shelf transport. Although much more remains to be done in forming quantitative comparisons between newly acquired data and model results, the above findings are at least all consistent with the simplified model experiments presented.

These model experiments are an initial element of a stepwise approach to in situ data collection and modeling aimed at furthering our understanding of the circulation's role in practical WFS environmental issues. The WFS supports highly productive commercial and recreational fisheries for which the Big Bend has particular significance (C. Keonig, personal communication, 1997). Pathways of larval transport between offshore spawning and nearshore juvenile development regions require explanation. The region south of Tampa Bay is known to be a "red-tide" epicenter region [Tester and Steidinger, 1997] that may also have a basis in the circulation. Through a coordinated use of in situ data and modeling we hope to achieve a quantitative framework in which to address such material property questions.

\section{Appendix: Turbulence Closure Submodel}

Vertical mixing of momentum in this study is parameterized by an eddy coefficient $\left(K_{m}+\nu\right)$, where $K_{m}$ is an instantaneous value obtained from the POM turbulence closure submodel and $\nu$ is a constant background value set to $2.0 \times 10^{-5} \mathrm{~m}^{2} \mathrm{~s}^{-1}$. The POM turbulence closure submodel is based on the works of Mellor and Yamada [1982] and Galperin et al. [1988], characterizing mixing by the equations for the turbulence kinetic energy $q^{2}$ and a turbulence macroscale $l$ according to the following:

$$
\begin{aligned}
& h_{1} h_{2} \frac{\partial\left(q^{2} D\right)}{\partial t}+\frac{\partial}{\partial \xi}\left(h_{2} u q^{2} D\right)+\frac{\partial}{\partial \varsigma}\left(h_{1} v q^{2} D\right)+h_{1} h_{2} \frac{\partial\left(q^{2} \omega\right)}{\partial \sigma} \\
& =h_{1} h_{2}\left\{\frac{2 K_{m}}{D}\left[\left(\frac{\partial u}{\partial \sigma}\right)^{2}+\left(\frac{\partial v}{\partial \sigma}\right)^{2}\right]+\frac{2 g}{\rho_{0}} K_{h} \frac{\partial \rho}{\partial \sigma}-\frac{2 D q^{3}}{B_{1} l}\right\} \\
& +\frac{\partial}{\partial \xi}\left(\frac{h_{2}}{h_{1}} A_{h} D \frac{\partial q^{2}}{\partial \xi}\right)+\frac{\partial}{\partial \varsigma}\left(\frac{h_{1}}{h_{2}} A_{h} D \frac{\partial q^{2}}{\partial \varsigma}\right) \\
& +h_{1} h_{2} \frac{\partial}{\partial \sigma}\left(\frac{K_{q}}{D} \frac{\partial q^{2}}{\partial \sigma}\right) \\
& h_{1} h_{2} \frac{\partial\left(q^{2} l D\right)}{\partial t}+\frac{\partial}{\partial \xi}\left(h_{2} u q^{2} l D\right)+\frac{\partial}{\partial \varsigma}\left(h_{1} v q^{2} l D\right)+h_{1} h_{2} \frac{\partial\left(q^{2} l \omega\right)}{\partial \sigma} \\
& =h_{1} h_{2}\left[\frac{1 E_{1} K_{m}}{D}\left[\left(\frac{\partial u}{\partial \sigma}\right)^{2}+\left(\frac{\partial v}{\partial \sigma}\right)^{2}\right]+\frac{l E_{1} g}{\rho_{0}} K_{h} \frac{\partial \sigma}{\partial \sigma}-\frac{q^{3} D}{B_{1}} \bar{\omega}\right\} \\
& +\frac{\partial}{\partial \xi}\left[\frac{h_{2}}{h_{1}} A_{h} D \frac{\partial\left(q^{2} l\right)}{\partial \xi}\right]+\frac{\partial}{\partial \varsigma}\left[\frac{h_{1}}{h_{2}} A_{h} D \frac{\partial\left(q^{2} l\right)}{\partial \varsigma}\right] \\
& +h_{1} h_{2} \frac{\partial}{\partial \sigma}\left[\frac{K_{q}}{D} \frac{\partial\left(q^{2} l\right)}{\partial \sigma}\right]
\end{aligned}
$$


where a wall proximity function $\bar{\omega}=1+E_{2}(l / \kappa L)^{2}$ is introduced with $(L)^{-1}=(\eta-D \sigma)^{-1}+\left(H_{0}+D \sigma\right)^{-1}$ and $B_{1}, E_{1}$, and $E_{2}$ are constants. Given the closure assumptions described by Mellor and Yamada [1982], the mixing coefficients for momentum, heat, and turbulent kinetic energy $K_{m}, K_{h}$, and $K_{q}$ are reduced to $K_{m}=l q S_{m}, K_{h}=l q S_{h}$, and $K_{q}=$ $l q S_{q}$, respectively, where $S_{m}, S_{h}$, and $S_{q}$ are stability functions, analytically derived from algebraic relations dependent on $\partial u / \partial \sigma, \partial v / \partial \sigma, g \rho_{0}^{-1}(\partial \rho / \partial \sigma), q$, and $l$. By introducing $G_{m}=\left(l^{2} / q^{2} D\right)\left[(\partial u / \partial \sigma)^{2}+(\partial v / \partial \sigma)^{2}\right]^{1 / 2}$ and $G_{h}=$ $\left(l^{2} / q^{2} D\right)\left(g / \rho_{0}\right)(\partial \rho / \partial \sigma)$, the stability functions become

$$
S_{q}=0.20
$$

$$
\begin{aligned}
& S_{m}\left[6 A_{1} A_{2} G_{m}\right]+S_{h}\left[1-2 A_{2} B_{2} G_{h}-12 A_{1} A_{2} G_{h}\right]=A_{2} \\
& S_{m}\left[1+6 A_{1}^{2} G_{m}-9 A_{1} A_{2} G_{h}\right]-S_{h}\left[12 A_{1}^{2} G_{h}+9 A_{1} A_{2} G_{h}\right] \\
& \quad=A_{1}\left(1-3 C_{-1}\right)
\end{aligned}
$$

The empirical constants are derived from laboratory data:

$$
\begin{aligned}
& \left(A_{1}, A_{2}, B_{1}, B_{2}, C_{1}, E_{1}, E_{2}\right) \\
& \quad=(0.92,0.74,16.6,10.1,0.08,1.8,1.33)
\end{aligned}
$$

The boundary conditions for $q^{2}$ and $l$ in this turbulence closure submodel are

$$
\begin{gathered}
q^{2}(0)=B_{1}^{2 / 3} u_{\tau s}(0) \\
q^{2}(-1)=B_{1}^{2 / 3} u_{x b}(-1) \\
q^{2} l(0)=0 \\
q^{2} l(-1)=0
\end{gathered}
$$

where $u_{\tau s}$ and $u_{\tau b}$ are the friction velocities calculated from the applied surface wind and the modeled bottom frictional stresses, respectively.

Acknowledgments. This research was supported by a cooperative agreement between the U.S. Geological Survey, Center for Coastal Geology, St. Petersburg, Florida, and the University of South Florida and by the U.S. Department of the Interior, Mineral Management Service, contract MMS 14-35-0001-30804. The authors thank K. Kusek for help with the manuscript. G. Mellor kindly provided helpful discussions for the implementation of the POM. Discussions with $\mathrm{H}$. Yang on model experimentation and analysis are also acknowledged.

\section{References}

Allen, J. S., P. A. Newberger, and J. Federiuk, Upwelling circulation on the Oregon continental shelf, I, Response to idealized forcing, $J$. Phys. Oceanogr., 25, 1843-1866, 1995.

Black, B. D., A description of the circulation on the west Florida continental shelf, M.S. thesis, Univ. of South Fla., St. Petersburg, 1998.

Blumberg, A. F., and L. H. Kantha, Open boundary conditions for circulation models, J. Hydraul. Eng., 111, 237-255, 1985.

Blumberg, A. F., and G. L. Mellor, A simulation of the circulation in the Gulf of Mexico, Isr. J. Earth Sci., 34, 122-144, 1985.

Blumberg, A. F., and G. L. Mellor, A description of a threedimensional coastal ocean circulation model, in Three-Dimensional Coastal Ocean Models, Coastal Estuarine Stud., vol. 4, edited by N. S. Heaps, pp. 208-233, AGU, Washington, D. C., 1987.

Chew, F., The summer circulation of the Florida west coast offshore water as deduced from the pattern of thermocline depths and a non-geostrophic equation of motion, Tech. Rep. 55-12, 6 pp., Univ. of Miami Mar. Lab., Miami, Fla., 1955.

Cooper, $\mathrm{C}$., A numerical modeling study of low-frequency circulation on the west Florida shelf, Coastal Eng., 11, 29-56, 1987.
Cragg, J., G. Mitchum, and W. Sturges, Wind-induced sea-surface slopes on the west Florida shelf, J. Phys. Oceanogr., 13, 2201-2212, 1983.

Csanady, G. T., The arrested topographic wave, J. Phys. Oceanogr., 8, 47-62, 1978.

Ezer, T., and G. Mellor, Continuous assimilation of Geosat altimeter data into a three-dimensional primitive equation Gulf Stream model, J. Phys. Oceanogr., 24, 832-847, 1994.

Galperin, B., L. H. Kantha, S. Hassid, and A. Rosati, A quasiequilibrium turbulent energy model for geophysical flows, J. Atmos. Sci., 45, 55-62, 1988.

Gilbes, F., C. Tomas, J. J. Walsh, and F. E. Muller-Karger, An episodic chlorophyll plume on the west Florida shelf, Cont. Shelf Res., 16, 1201-1224, 1996

Gill, A. E., Atmosphere-Ocean Dynamics, 662 pp., Academic, San Diego, Calif., 1982.

Hsueh, Y., G. O. Marmorino, and L. Vansant, Numerical model studies of the winter-storm response of the west Florida shelf, $J$. Phys. Oceanogr., 12, 1037-1050, 1982.

Koblinsky, C. J., and P. P. Niiler, Direct measurements of circulation on west Florida continental shelf, January 1973-May 1975, Data Rep. 76, Ref. 79-13, 102 pp., School of Oceanogr., Oreg. State Univ., 1980.

Lentz, S. J., Sensitivity of the inner-shelf circulation to the form of the eddy viscosity profile, $J$. Phys. Oceanogr., 25, 19-28, 1995.

$\mathrm{Li}, \mathrm{Z}$., Upwelling circulation on the west Florida continental shelf, Ph.D. thesis, 309 pp., Univ. of South Fla., St. Petersburg, 1998.

Marmorino, G. O., Wind-forced sea level variability along the west Florida shelf (winter, 1978), J. Phys. Oceanogr., 12, 389-405, 1982.

Marmorino, G. O., Variability of current, temperature, and bottom pressure across the west Florida continental shelf, winter, 19811982, J. Geophys. Res., 88(C7), 4439-4457, 1983.

Mellor, G. L., and T. Yamada, A hierarchy of turbulence closure models for planetary boundary layers, J. Atmos. Sci., 13, 1791-1806, 1974.

Mellor, G. L., and T. Yamada, Development of a turbulence closure model for geophysical fluid problems, Rev. Geophys., 20, 851-875, 1982.

Miller, J. L., and T. N. Lee, Gulf stream meanders in the South Atlantic Bight, 1, Scaling and energetics, J. Geophys. Res., 100, 66876704, 1995a.

Miller, J. L., and T. N. Lee, Gulf stream meanders in the South Atlantic Bight, 2, Momentum balances, J. Geophys. Res., 100, 6705$6723,1995 \mathrm{~b}$.

Mitchum, T. G., and A. J. Clarke, The frictional nearshore response to forcing by synoptic scale winds, J. Phys. Oceanogr., 16, 934-946, 1986a.

Mitchum, T. G., and A. J. Clarke, Evaluation of frictional, wind forced long wave theory on the west Florida shelf, J. Phys. Oceanogr., 16, 1029-1037, 1986b.

Mitchum, G., and W. Sturges, Wind-driven currents on the west Florida shelf, J. Phys. Oceanogr., 12, 1310-1317, 1982.

Niiler, P. P., Observations of low-frequency currents on the west Florida continental shelf, Mem. Soc. $R$. Sci. Liège Collect. $6^{e}, 10,331-358$, 1976.

Oey, L.-Y., Eddy- and wind-forced shelf circulation, J. Geophys. Res., $100,8621-8637,1995$.

Orlanski, I., A simple boundary condition for unbounded hyperbolic flows, J. Comput. Phys., 21, 251-269, 1976.

Paluszkiewicz, T., L. Atkinson, E. S. Parmentier, and C. R. McClain, Observations of a loop current frontal eddy intrusion onto the west Florida shelf, J. Geophys. Res., 88, 9639-9651, 1983.

Philander, S. G. H., and J. H. Yoon, Eastern boundary currents and coastal upwelling, J. Phys. Oceanogr., 12, 862-879, 1982.

Siegel, E., Currents observed across the west Florida continental shelf, M.S. thesis, 155 pp., Univ. of South Fla., St. Petersburg, 1999.

Suginohara, J., Coastal upwelling: Onshore-offshore circulation, equatorward coastal jet and poleward undercurrent over a continental shelf-slope, J. Phys. Oceanogr., 12, 272-284, 1982.

Tester, P. A., and K. A. Steidinger, Gymnodinium breve red tide blooms: Initiation, transport, and consequences of surface circulation., Limnol. Oceanogr., 42(5), 1039-1052, 1997.

Weatherly, G. L., and D. Thistle, On the wintertime currents in the Florida Big Bend region, Cont. Shelf Res., 17, 1297-1319, 1997.

Weisberg, R. H., B. D. Black, and H. Yang, Seasonal modulation of 
the west Florida continental shelf circulation, Geophys. Res. Lett., 23, 2247-2250, 1996a.

Weisberg, R. H., B. D. Black, J. C. Donovan, and R. D. Cole, The west-central Florida shelf hydrography and circulation study: A report on data collected using a surface moored acoustic Doppler current profiler, October 1993-January 1995, data report, Dep. of Mar. Sci., Univ. of South Fla., St. Petersburg, Jan. 1996b.

Winant, C. D., Comments on "The arrested topographic wave," J. Phys. Oceanogr., 9, 1042-1043, 1979.

Yang, H., R. H. Weisberg, P. P. Niiler, W. Sturges, and W. Johnson,
Lagrangian circulation and forbidden zone on the west Florida shelf, Cont. Shelf Res., in press, 1999.

Z. Li and R. H. Weisberg, Department of Marine Science, University of South Florida, 140 Seventh Avenue South, St. Petersburg, FL 33701-5016. (weisberg@ocg6.marine.usf.edu)

(Received September 10, 1997; revised December 18, 1998; accepted February 2, 1999.) 